\title{
Drug Interactions with New and Investigational Antiretrovirals
}

\author{
Kevin C. Brown, Sunita Paul, and Angela D.M. Kashuba \\ School of Pharmacy, Center for AIDS Research Clinical Pharmacology and Analytical Chemistry \\ Core, University of North Carolina at Chapel Hill, Chapel Hill, North Carolina, USA
}

\section{Abstract}

More than 20 individual and fixed-dose combinations of antiretrovirals are approved for the treatment of human immunodeficiency virus (HIV) infection. However, owing to the ongoing limitations of drug resistance and adverse effects, new treatment options are still required. A number of promising new agents in existing or new drug classes are in development or have recently been approved by the US FDA. Since these agents will be used in combination with other new and existing antiretrovirals, understanding the potential for drug interactions between these compounds is critical to their appropriate use. This article summarizes the drug interaction potential of new and investigational protease inhibitors (darunavir), non-nucleoside reverse transcriptase inhibitors (etravirine and rilpivirine), chemokine receptor antagonists (maraviroc, vicriviroc and INCB 9471), integrase inhibitors (raltegravir and elvitegravir) and maturation inhibitors (bevirimat).

Advances in the treatment of human immunodeficiency virus (HIV) infection include the discovery of new antiretroviral agents and an improved understanding of the optimal combination of these agents for therapeutic benefit. Currently, the most potent antiretroviral regimens are those that include a combination of medications targeting different stages of the HIV life cycle. In 2007, two new classes of antiretrovirals were approved by the US FDA, and a number of other novel antiretrovirals in new classes and existing classes are being developed. All of these drugs are promising options for treatment-experienced patients. However, each class has a unique drug-interaction profile, making the optimal combination of these drugs challenging. Encouragingly, some of these new agents are not substrates of either cytochrome P450 (CYP) enzymes or drug transport proteins. This increases their potential to be used in combination with currently available antiretroviral agents without concern for subtherapeutic or supratherapeutic exposures. This article reviews the drug-drug interaction data, as well as drug-drug interaction potential, for antiretrovirals that have recently become available or are currently undergoing later phase clinical study. New protease inhibitors and non-nucleoside reverse transcriptase inhibitors (NNRTIs) are featured, as are new agents in the chemokine receptor antagonist class, the integrase inhibitor class, and the maturation inhibitor class. A summary of interactions between antiretrovirals can be found in tables I-III, and a summary of interactions between these new antiretrovirals and concomitant medications is presented in table IV.

(C) 2009 Adis Data Information BV. All rights reserved.

Correspondence: Dr Angela D.M. Kashuba, School of Pharmacy, University of North Carolina at Chapel Hill, 3318 Kerr Hall, CB\# 7360, Chapel Hill, NC 27599-7360, USA. akashuba@unc.edu.

The other authors have no conflicts of interest that are directly relevant to the content of this review. 


\section{Protease Inhibitors}

\subsection{Darunavir}

Darunavir is a new protease inhibitor recently approved for the treatment of HIV-1-infected patients. In the US, the approved dose of darunavir is $600 \mathrm{mg}$, administered in conjunction with $100 \mathrm{mg}$ of ritonavir, every 12 hours with food. Darunavir is recommended for use in treatment-experienced (multiple protease inhibitor-resistant) adult patients (figure 1a).

1.1.1 Pharmacology-The molecular weight of darunavir is $593.73 \mathrm{~g} / \mathrm{mol}$.[1] Darunavir maintains activity against multidrug-resistant strains of HIV-1. This may be due, in part, to darunavir's higher binding affinity to the HIV protease enzyme. The derived binding affinity constant of darunavir is $>0.0045 \mathrm{nmol} / \mathrm{L}$, which is approximately 1000 -fold greater than those of indinavir, nelfinavir and saquinavir.[2] Darunavir maintains a binding affinity that is more than 100-fold higher than those of amprenavir, atazanavir, lopinavir and tipranavir in the presence of wild-type protease. Darunavir's dissociative half-life from the protease enzyme is also much higher ( $>240$ hours) than those of other protease inhibitors, suggesting that darunavir remains bound and active in vivo throughout the plasma elimination process. [3]

The median concentration at which 50\% of the maximum darunavir drug effect is achieved $\left(\mathrm{EC}_{50}\right)$ ranges from 1 to $8.5 \mathrm{nmol} / \mathrm{L}$.[1] The $90 \%$ effective concentration ranges from 2.7 to $13 \mathrm{nmol} / \mathrm{L}$.[2] Darunavir is approximately $95 \%$ bound to plasma $\alpha_{1}$-acid glycoprotein.[1] In vitro observations of clinically relevant darunavir plasma concentrations at 4.7 to 52 baseequivalent $\mathrm{ng} / \mathrm{mL}$ found that the mean plasma protein binding of darunavir ranges from $92 \%$ to $94 \%$.[4] As expected, when darunavir concentrations increase within this in vitro system, the fraction of unbound darunavir increases. A study of 118 HIV-positive, treatmentexperienced individuals calculated a median inhibitory quotient (IQ) of 36.3 (range 0.51150), assuming $95 \%$ protein binding in the calculation of free drug concentration.[5]

In vitro, the major mechanism of darunavir absorption is through passive transcellular diffusion. However, darunavir is both a substrate and an inhibitor of the enzyme Pglycoprotein (with an apparent 50\% inhibitory concentration [ $\mathrm{IC}_{50}$ ] of $32.9 \mu \mathrm{mol} / \mathrm{L}$, or 19 $\mu \mathrm{g} / \mathrm{mL}$ ). Since darunavir is coadministered with ritonavir (also a P-glycoprotein inhibitor), it is possible that this combination could affect the intestinal absorption of other compounds that are also substrates of P-glycoprotein.[6] However, no full-intensive pharmacokinetic studies investigating any clinically relevant drug-drug interactions between darunavir/ ritonavir and other P-glycoprotein substrates have been conducted. Evaluation of the function of the efflux transporter multidrug resistance protein (MRP) 1 in a group of seven healthy volunteers who took $900 \mathrm{mg}$ of darunavir and $100 \mathrm{mg}$ of ritonavir once daily for 10 days resulted in decreased MRP1 expression without decreased messenger RNA expression or efflux function in vivo. Compared with baseline, the geometric mean ratio (GMR) for MRP1 expression declined by 0.58 (95\% CI 0.51, 0.65; $\mathrm{p}<0.001)$. The expression of MRP1 was $41 \%$ higher (GMR 1.41) in CD4 cells than in all peripheral blood mononuclear cells (PBMCs).[7]

Darunavir is metabolized almost exclusively by the hepatic CYP3A4 enzyme.[8] Three major metabolites of darunavir have been identified, all of which demonstrate at least $90 \%$ less activity against wild-type HIV strains in comparison with darunavir. The darunavir metabolite M19 forms by carbamate hydrolysis, metabolite M23 forms through aliphatic hydroxylation, and metabolite M29 forms through aromatic hydroxylation. Three minor darunavir metabolites have also been identified: M27 and M28 both form by alicyclic hydroxylation and metabolite M6 forms through an unspecified pathway.[9] 
In human liver microsomes, darunavir inhibits the activity of CYP1A2, CYP2C9, CYP2C19 and CYP2D6.[10] In human hepatocytes, and in human subjects, darunavir induces CYP3A4 activity. As a CYP3A4 substrate, darunavir also demonstrates competitive inhibition of CYP3A4, yielding an inhibitory constant $\left(\mathrm{K}_{\mathrm{i}}\right)$ value of $0.40 \mu \mathrm{mol} / \mathrm{L}(0.22 \mu \mathrm{g} /$ $\mathrm{mL}$ ), which is within the range of clinical relevance. When darunavir is administered with other CYP3A4 inhibitors (such as ritonavir), the net result is inhibition of CYP3A4 activity. [10] Since darunavir's $K_{i}$ values for CYP2B6, CYP2C9, CYP2C19 and CYP2D6 are at least 60-fold higher than for CYP3A4, there is less potential for clinically relevant drug-drug interactions through these enzymes.[9]

1.1.2 Pharmacokinetics-The absolute bioavailability of a $600 \mathrm{mg}$ dose of darunavir is $37 \%$. The addition of $100 \mathrm{mg}$ of ritonavir increases the bioavailability to $82 \%$. Owing to an overall net inhibition of CYP3A4 and P-glycoprotein activity, coadministration of ritonavir with darunavir results in a 14-fold increase in the darunavir area under the plasma concentration-time curve (AUC) compared with administration of darunavir alone.[11]

In healthy volunteers, the median terminal elimination half-life is 15 (range 12.7-16.4) hours.[4] In a study of a single $150 \mathrm{mg}$ intravenous dose administered after 2 days of oral ritonavir given $100 \mathrm{mg}$ twice daily, the mean volume of distribution was $131 \mathrm{~L}$.[2] Pharmacokinetic parameters for darunavir obtained from 119 HIV-positive participants included a median steady-state AUC over a 12-hour dosing interval $\left(\mathrm{AUC}_{12}\right)$ of 61668 (range $33857-106490) \mathrm{ng} \cdot \mathrm{h} / \mathrm{mL}$ and a median trough plasma concentration $\left(\mathrm{C}_{\text {trough }}\right)$ of 3539 (range 1255-7368) ng/mL.[1]

Food increases the bioavailability of darunavir when coadministered with ritonavir by approximately $30 \%$, regardless of the composition of the meal.[12] Most of darunavir $(81.7 \%)$ is eliminated through faeces and $12.2 \%$ is eliminated through urine. The proportion of unchanged darunavir eliminated in the faeces is $6.8 \%$ when administered alone and $41.2 \%$ when administered with ritonavir.[11]

1.1.3 Drug-Drug Interactions-Significant drug-drug interactions occur between darunavir/ritonavir and certain other antiretrovirals and anti-infectives, HMG Co-A reductase inhibitors, phosphodiesterase inhibitors, oral contraceptives and selective serotonin reuptake inhibitors (SSRIs). Many of these interactions predictably occurred through inhibition or induction of CYP3A4,[13] although some were unexpected.

Darunavir/Ritonavir and Protease Inhibitors: A 14-day evaluation in healthy subjects coadministered darunavir/ritonavir $400 \mathrm{mg} / 100 \mathrm{mg}$ with saquinavir $1000 \mathrm{mg}$ in hard-gel capsule formulation observed a reduction in darunavir exposure. The darunavir $\mathrm{AUC}_{12}$, peak plasma concentration $\left(\mathrm{C}_{\max }\right)$ and minimum plasma concentration $\left(\mathrm{C}_{\min }\right)$ decreased by a mean of $26 \%, 17 \%$ and $42 \%$, respectively. Saquinavir exposure also slightly decreased: the $\mathrm{AUC}_{12}$ and $\mathrm{C}_{\max }$ by $6 \%$ and the $\mathrm{C}_{\min }$ by $18 \%$. Additionally, the combined administration of darunavir, ritonavir and saquinavir was associated with an increased incidence of adverse events and trial discontinuations.[14] Because of these observations, it is recommended that saquinavir and darunavir not be administered together.

Two studies in healthy subjects investigated dosing strategies to overcome a decline in darunavir exposure when combined with lopinavir/ritonavir. In one study, darunavir/ ritonavir was administered at $1200 \mathrm{mg} / 100 \mathrm{mg}$ twice daily in combination with standard lopinavir/ritonavir $400 \mathrm{mg} / 100 \mathrm{mg}$ twice daily. In the second study, darunavir/ritonavir was administered at $1200 \mathrm{mg} / 100 \mathrm{mg}$ twice daily in combination with increased lopinavir/ ritonavir $533 \mathrm{mg} / 133 \mathrm{mg}$ twice daily. Both strategies failed to prevent a decrease in darunavir exposure. When the darunavir dose was doubled, the $\mathrm{AUC}_{12}, \mathrm{C}_{\max }$ and $\mathrm{C}_{\min }$ 
decreased by $38 \%, 21 \%$ and $51 \%$, respectively. When the darunavir dose was doubled and the lopinavir/ritonavir dose was increased, the darunavir $\mathrm{AUC}_{12}, \mathrm{C}_{\max }$ and $\mathrm{C}_{\min }$ decreased by $41 \%, 21 \%$ and $55 \%$, respectively. Lopinavir exposure was minimally influenced in both trials $\left(\sim 9 \%\right.$ increase in the $\left.\mathrm{AUC}_{12}\right)$. In contrast to the saquinavir investigations, no increases in adverse events were reported with this combination of protease inhibitors. However, based on the pharmacokinetic interaction, coadministration of darunavir/ritonavir with lopinavir is not recommended.[15]

The interaction between indinavir and darunavir/ritonavir was studied using a dose of darunavir that is lower than the currently licensed dose. Twice-daily administration of indinavir $800 \mathrm{mg}$ with darunavir/ritonavir $400 \mathrm{mg} / 100 \mathrm{mg}$ increased both indinavir and darunavir concentrations. The AUC and $\mathrm{C}_{\min }$ of indinavir increased by $23 \%$ and $125 \%$, respectively, while the AUC and $\mathrm{C}_{\min }$ of darunavir increased by $24 \%$ and $44 \%$, respectively. Although the appropriate dose of indinavir given in combination with darunavir/ritonavir has not yet been established, in cases of intolerance to this combination, it is suggested that the indinavir dose be reduced from $800 \mathrm{mg}$ to $600 \mathrm{mg}$ twice daily.[16]

The interaction between atazanavir and darunavir/ritonavir was also studied using a lower than currently licensed dose of darunavir. Coadministration of atazanavir $300 \mathrm{mg}$ once daily with darunavir/ritonavir $400 \mathrm{mg} / 100 \mathrm{mg}$ twice daily had no significant effect upon the AUC and $\mathrm{C}_{\min }$ of either atazanavir or darunavir in a study of 13 healthy subjects. The $\mathrm{C}_{\max }$, AUC and $\mathrm{C}_{\min }$ of darunavir increased by only $2 \%, 3 \%$ and $1 \%$, respectively. Compared with atazanavir exposure when atazanavir/ritonavir was given alone, the $\mathrm{C}_{\max }$ decreased by a mean of $11 \%$, the AUC increased by $8 \%$ and the $\mathrm{C}_{\text {min }}$ increased by $52 \%$. Based on these results, no adjustment in dose is considered necessary when atazanavir is administered with darunavir/ritonavir.[16]

Darunavir/Ritonavir and Entry Inhibitors: Since maraviroc is a CYP3A4 substrate (see section 3.1 for more details), concomitant administration with darunavir/ritonavir was predicted to increase maraviroc exposure. Therefore, in a 10-day, two-way crossover drug interaction study in healthy subjects, a 50\% lower dose than the standard recommended dose of maraviroc was used. When administered at $150 \mathrm{mg}$ twice daily in combination with darunavir/ritonavir or placebo, the $\mathrm{AUC}_{12}$ and $\mathrm{C}_{\max }$ of maraviroc were 2.3- to 4-fold higher with darunavir/ritonavir than with placebo. Darunavir/ritonavir exposures were not significantly altered. These results are consistent with findings from other studies[17,18] administering maraviroc with ritonavir-boosted protease inhibitors.[19] Thus, when coadministered with darunavir/ritonavir, the maraviroc dosage should be reduced by $50 \%$ to $150 \mathrm{mg}$ twice daily.

A combination of twice-daily therapy with $90 \mathrm{mg}$ of the fusion inhibitor enfuvirtide and standard darunavir/ritonavir dosage has been studied in HIV-infected patients. No difference was observed between the pharmacokinetic parameters of darunavir in the presence of enfuvirtide and the pharmacokinetic parameters of darunavir administered alone. The effects of darunavir/ritonavir on enfuvirtide have not been investigated.[20,21]

Darunavir/Ritonavir and Reverse Transcriptase Inhibitors: No dose adjustment is warranted when darunavir is coadministered with nevirapine, tenofovir and etravirine. The combination of darunavir with efavirenz should be used with caution.[8]

Nevirapine is a substrate and inducer of CYP3A4 enzyme activity. When darunavir/ritonavir $400 \mathrm{mg} / 100 \mathrm{mg}$ was added to a stable antiretroviral regimen that contained nevirapine 200 mg twice daily, in a study of HIV-positive individuals, the combination resulted in a $24 \%$ increase in the mean $\mathrm{AUC}_{12}$ of darunavir, a $40 \%$ increase in the mean $\mathrm{C}_{\max }$ and no influence 
on the $\mathrm{C}_{\min }$. This combination resulted in increases in the nevirapine $\mathrm{AUC}_{12}$ and $\mathrm{C}_{\min }$ (by $27 \%$ and $47 \%$, respectively), while no significant effect on the $\mathrm{C}_{\max }$ was observed. Based on these results, no dose adjustment is necessary in the coadministration of darunavir/ritonavir with nevirapine.[22]

A modest interaction has been observed with the coadministration of darunavir/ritonavir 300 $\mathrm{mg} / 100 \mathrm{mg}$ and tenofovir $300 \mathrm{mg}$. The pharmacokinetic parameters of this combination were evaluated in a randomized, crossover study in 12 healthy subjects. When administered with darunavir/ritonavir, the tenofovir AUC from 0 to 24 hours $\left(\mathrm{AUC}_{24}\right), \mathrm{C}_{\max }$ and $\mathrm{C}_{\min }$ increased by a mean of $22 \%, 24 \%$ and $37 \%$, respectively. When administered with tenofovir, the darunavir $\mathrm{AUC}_{12}, \mathrm{C}_{\max }$ and $\mathrm{C}_{\min }$ were increased by a mean of $21 \%, 16 \%$ and $24 \%$, respectively. Since these are only modest increases with no observed increase in adverse events, no dose adjustment is necessary with this combination.[23]

Etravirine is a new NNRTI recently approved by the FDA. The pharmacokinetic interaction between etravirine (100 or $200 \mathrm{mg}$ twice daily, phase III formulation) and darunavir/ ritonavir ( $600 \mathrm{mg} / 100 \mathrm{mg}$ twice daily) has been investigated in 23 healthy subjects. Coadministration of etravirine $100 \mathrm{mg}$ with darunavir/ritonavir decreased the etravirine $\mathrm{AUC}_{12}, \mathrm{C}_{\max }$ and $\mathrm{C}_{\min }$ by a mean of $37 \%, 32 \%$ and $49 \%$, respectively. Increasing the dose of etravirine to $200 \mathrm{mg}$ (the dose approved by the FDA) resulted in increases in the etravirine $\mathrm{AUC}_{12}, \mathrm{C}_{\max }$ and $\mathrm{C}_{\min }$ by a mean of $80 \%, 81 \%$ and $67 \%$, respectively, compared with etravirine $100 \mathrm{mg}$ given alone.

Compared with the observed exposure of darunavir administered alone, no significant change in darunavir exposure occurred when darunavir was given with etravirine in studies of HIV-infected patients. [24] Phase III trials of etravirine indicate that safe and effective etravirine exposures are achieved when etravirine is administered in combination with darunavir and ritonavir.[25] Thus, etravirine can be given in combination with darunavir/ ritonavir at the approved dose of $200 \mathrm{mg}$ twice daily without any dose adjustments.[26]

Since darunavir/ritonavir inhibits CYP3A4 and efavirenz induces CYP3A4, a decrease in darunavir exposure and an increase in efavirenz exposure would be predicted for these drugs when administered concomitantly. This was confirmed in a study in healthy subjects with the combination of darunavir/ritonavir $300 \mathrm{mg} / 100 \mathrm{mg}$ given twice daily and efavirenz 600 $\mathrm{mg}$ given once daily. With this combination, the $\mathrm{C}_{\min }$ and $\mathrm{C}_{\max }$ of efavirenz increased by a mean of $15 \%$ to $17 \%$, respectively, while the $\mathrm{AUC}_{24}$ increased by $21 \%$. Darunavir exposure decreased with this combination: the $\mathrm{C}_{\min }$ by $31 \%$, the $\mathrm{C}_{\max }$ by $15 \%$ and the $\mathrm{AUC}_{12}$ by 13\%.[27] The combination of darunavir with efavirenz should be used with caution. No dose adjustment is recommended for this combination, but clinical monitoring for toxicity associated with increased exposure to efavirenz should be considered.

Darunavir/Ritonavir and HMG-CoA Reductase Inhibitors: Atorvastatin is an HMGCoA reductase inhibitor commonly used by HIV-infected patients for the management of hyperlipidaemia. Atorvastatin is $>98 \%$ bound to plasma proteins and is extensively metabolized by CYP3A4 to active metabolites, which accounts for $~ 70 \%$ of HMG-CoA reductase inhibitory activity.[28] In a pharmacokinetic study that expected an inhibitory effect of darunavir/ritonavir on the metabolism of atorvastatin, darunavir/ritonavir $300 \mathrm{mg}$ / $100 \mathrm{mg}$ given twice daily was combined with atorvastatin $10 \mathrm{mg}$ given daily to ten healthy subjects. The pharmacokinetics of $40 \mathrm{mg}$ of atorvastatin administered alone were compared with the pharmacokinetics of $10 \mathrm{mg}$ of atorvastatin administered daily and coadministered with darunavir/ritonavir $300 \mathrm{mg} / 100 \mathrm{mg}$ twice daily ( $\mathrm{n}=15$ healthy subjects). The $10 \mathrm{mg}$ dose of atorvastatin administered with darunavir/ritonavir had an $\mathrm{AUC}_{24}$ that was only $15 \%$ lower than that of the standard $40 \mathrm{mg}$ dose of atorvastatin administered alone. Atorvastatin 
did not significantly affect the pharmacokinetics of darunavir/ritonavir. Therefore, it is recommended that atorvastatin $10 \mathrm{mg}$ once daily be utilized by patients receiving darunavir/ ritonavir to provide atorvastatin exposures similar to $40 \mathrm{mg}$ when given alone.[29]

A study of 14 healthy subjects given pravastatin $40 \mathrm{mg}$ with or without darunavir/ritonavir found a significant increase in pravastatin exposures. Darunavir/ritonavir increased the $\mathrm{C}_{\max }$ of pravastatin by an average of $63 \%$ (from a mean \pm SD of $50.9 \pm 67.6$ to $86.9 \pm 88.4 \mathrm{ng}$ / $\mathrm{mL}$ ), the $\mathrm{AUC}_{24}$ by $81 \%$ (from $92.0 \pm 86.4$ to $175 \pm 159 \mathrm{ng} \bullet \mathrm{h} / \mathrm{mL}$ ) and the time to reach the maximum concentration $\left(\mathrm{t}_{\max }\right)$ by $50 \%$ (from 1.0 to 1.5 hours). Therefore, it is recommended that pravastatin be initiated at the lowest possible dose in patients receiving darunavir/ritonavir, and then increased gradually with careful monitoring.[30]

Darunavir/Ritonavir and Oral Contraceptives: When administered concurrently with darunavir/ritonavir, hormonal contraceptive concentrations decline significantly. When darunavir/ritonavir $600 \mathrm{mg} / 100 \mathrm{mg}$ twice daily was administered in combination with daily ethinylestradiol $0.035 \mathrm{mg}$ and norethisterone (norethindrone) $1.0 \mathrm{mg}$ (Ortho-Novum ${ }^{\circledR} 1 / 35$ ) in $19 \mathrm{HIV}$-infected women, the mean ethinylestradiol $\mathrm{AUC}_{24}, \mathrm{C}_{\max }$ and $\mathrm{C}_{\min }$ declined $44 \%$, $32 \%$ and $62 \%$, respectively. The mean $\mathrm{AUC}_{24}, \mathrm{C}_{\max }$ and $\mathrm{C}_{\min }$ of norethisterone declined $14 \%, 10 \%$ and $30 \%$, respectively. Darunavir/ritonavir concentrations were not significantly altered. Pharmacodynamic analyses of the serum concentrations of progesterone, luteinizing hormone and follicle-stimulating hormone showed a lesser suppression of hormone concentrations when darunavir/ritonavir was administered in conjunction with OrthoNovum ${ }^{\circledR} 1 / 35$ than with administration of Ortho-Novum ${ }^{\circledR} 1 / 35$ alone. These results suggest that oral contraceptives may have reduced efficacy when administered with darunavir/ ritonavir.[31]

Darunavir/Ritonavir and Phosphodiesterase 5 Inhibitors: Sildenafil, vardenafil and tadalafil are approved for the treatment of erectile dysfunction. These compounds are predominantly metabolized by CYP3A4 and have strong recommendations for dose reduction when given concurrently with other protease inhibitors.[32] The effects of darunavir/ritonavir $400 \mathrm{mg} / 100 \mathrm{mg}$ administered twice daily to steady state on the pharmacokinetics of a single $25 \mathrm{mg}$ dose of sildenafil were examined in 16 healthy male subjects. The sildenafil $\mathrm{C}_{\max }$ decreased by $38 \%$ when sildenafil $25 \mathrm{mg}$ was coadministered with darunavir/ritonavir, compared with when sildenafil 100mg was administered alone. Darunavir plasma concentrations were not affected by this single dose. Therefore, a dosereduction recommendation for coadministration of phosphodiesterase 5 inhibitors with darunavir/ritonavir is as follows: a single dose of sildenafil not exceeding $25 \mathrm{mg}$ within a 48 hour time period, a single dose of vardenafil not exceeding $2.5 \mathrm{mg}$ within a 72 -hour time period and a single dose of tadalafil not exceeding $10 \mathrm{mg}$ within a 72 -hour time period.[1]

Darunavir/Ritonavir and Selective Serotonin Reuptake Inhibitors: SSRIs are commonly used in HIV-infected patients. Sertraline is primarily metabolized by CYP3A4 and paroxetine is metabolized by CYP2D6. Drug-drug interactions between darunavir/ritonavir, paroxetine and sertraline were investigated in a randomized, multiple-dose, crossover study in 36 healthy subjects. Combined administration of darunavir/ritonavir $400 \mathrm{mg} / 100 \mathrm{mg}$ twice daily with either paroxetine $20 \mathrm{mg}$ once daily or sertraline $50 \mathrm{mg}$ once daily were compared with the administration of these drugs alone. The paroxetine $\mathrm{AUC}_{12}, \mathrm{C}_{\max }$ and $\mathrm{C}_{\min }$ decreased by a mean of $39 \%, 36 \%$ and $37 \%$, respectively, while the fraction of unbound (free) paroxetine increased by $25-35 \%$. The sertraline $\mathrm{AUC}_{12}, \mathrm{C}_{\max }$ and $\mathrm{C}_{\min }$ decreased by a mean of $49 \%, 44 \%$ and $49 \%$, respectively, while the fraction of unbound sertraline was not altered. Darunavir/ritonavir exposure was not significantly altered, and the drug combinations were well tolerated.[33] Since the exact correlation between the SSRI concentration and clinical response has not been defined, the clinical significance of the 
reduction in exposure is unknown. No empirical dose adjustment for paroxetine or sertraline is currently recommended, although closely monitored dose titration may be warranted.

Darunavir/Ritonavir and Anti-Infectives: Rifabutin is both an inducer and a substrate of CYP3A enzymes. Although no data are available for this interaction, coadministration of darunavir/ritonavir is expected to increase rifabutin concentrations and decrease darunavir concentrations, similarly to other ritonavir-boosted protease inhibitors. If coadministration is necessary, it is suggested that rifabutin be administered $150 \mathrm{mg}$ every other day or three times weekly.[1]

Rifampicin (rifampin) is a potent inducer of CYP3A4 enzyme activity. Coadministration of rifampicin with most protease inhibitors significantly decreases their plasma concentrations. Thus, it is anticipated that coadministration of darunavir with rifampicin will cause a significant decrease in darunavir plasma concentrations. No data are currently available on the pharmacokinetics of darunavir in the presence of rifampicin, but coadministration of these two agents is not recommended.[1]

Clarithromycin is a macrolide antibacterial agent indicated for prophylaxis and treatment of Mycobacterium avium complex. Clarithromycin is also commonly used to treat pharyngitis, tonsillitis and upper respiratory infections such as Chlamydia pneumoniae and Streptococcus pneumoniae.[34] The primary and active metabolite of clarithromycin, 14hydroxy-clarithromycin, is produced through CYP3A-mediated oxidation, $N$-demethylation, and hydroxylation.[35] Clarithromycin inhibits CYP3A enzyme activity and thus has the potential for significant interaction with protease inhibitors. Although no significant interaction has been observed between clarithromycin and the overall exposure of ritonavir in plasma, ritonavir increases the exposure of clarithromycin by $77 \%$ and extensively inhibits the formation of 14-hydroxy-clarithromycin.[36] The pharmacokinetics of the coadministration of darunavir/ritonavir $400 \mathrm{mg} / 100 \mathrm{mg}$ twice daily and clarithromycin 500 $\mathrm{mg}$ twice daily were examined in a three-way crossover study in 18 healthy subjects. Pharmacokinetic assessments were performed after 7 days. The $\mathrm{AUC}_{12}$ and $\mathrm{C}_{\max }$ of darunavir decreased by $17 \%$ and $13 \%$, respectively. The least square mean AUC ratio of darunavir administered alone compared with coadministration with clarithromycin was 0.87 $(90 \%$ CI $0.75,1.01)$. The least square mean ratio for the $\mathrm{C}_{\max }$ of darunavir administered alone compared with coadministration with clarithromycin was 0.83 (90\% CI 0.72, 0.96). The $\mathrm{AUC}_{12}$ and $\mathrm{C}_{\max }$ of clarithromycin increased by $57 \%$ and $26 \%$, respectively. The least square mean AUC ratio of clarithromycin administered alone compared with coadministration with darunavir was 1.57 (90\% CI 1.35, 1.84). The least square mean ratio for the $\mathrm{C}_{\max }$ of clarithromycin administered alone compared with coadministration with darunavir was 1.26 (90\% CI 1.03, 1.54). All concentrations of 14-hydroxy-clarithromycin were below the lower limit of quantification $(50 \mathrm{ng} / \mathrm{mL})$.[17] Similar variations in the pharmacokinetics of clarithromycin have been reported when clarithromycin was administered in conjunction with other protease inhibitors, and these variations have had little effect upon clinical outcome.[36-38] Since it is unlikely that the observed changes in exposure will have clinical significance, no dose adjustment is required for darunavir or clarithromycin in patients with normal renal function. A 50\% dose reduction is recommended for clarithromycin when coadministered with darunavir for individuals with creatinine clearance of $30-60 \mathrm{~mL} / \mathrm{min}$. A $75 \%$ clarithromycin dose reduction is recommended for individuals with creatinine clearance of $<30 \mathrm{~mL} / \mathrm{min}$.[1]

Ketoconazole is both a substrate and an inhibitor of CYP3A4. A study in 15 healthy subjects demonstrated that the combination of twice-daily darunavir/ritonavir $400 \mathrm{mg} / 100 \mathrm{mg}$ and ketoconazole $200 \mathrm{mg}$ increased the darunavir $\mathrm{AUC}_{12}$ by $42 \%$, the $\mathrm{C}_{\max }$ by $21 \%$ and the $\mathrm{C}_{\min }$ by $73 \%$. The mean $\mathrm{AUC}_{12}, \mathrm{C}_{\max }$ and $\mathrm{C}_{\min }$ of ketoconazole increased by $212 \%, 111 \%$ 
and $868 \%$, respectively. Based on these data, it is recommended that ketoconazole should not be given at doses greater than $200 \mathrm{mg}$ once daily when combined with darunavir/ ritonavir. Although there are no data, the effects on itraconazole are expected to be similar, and thus a maximum daily dose of $200 \mathrm{mg}$ is also recommended.[39] No data currently exist for the interaction between fluconazole and darunavir/ritonavir, although a clinical trial to investigate these effects is currently under way. Given that fluconazole is a moderate inhibitor of CYP3A4 enzyme activity, it is anticipated that plasma concentrations of darunavir will increase, and a dose adjustment may be warranted.

Darunavir/Ritonavir and Acid-Reducing Agents: Gastrointestinal issues are common among patients with HIV infection, and symptoms are often treated with acid-reducing agents such as histamine $\mathrm{H}_{2}$-receptor antagonists (e.g. ranitidine) or proton pump inhibitors (e.g. omeprazole). A multiple-dose study conducted in 16 healthy subjects compared the pharmacokinetics of darunavir/ritonavir $400 \mathrm{mg} / 100 \mathrm{mg}$ administered twice daily alone with those in combination with ranitidine $150 \mathrm{mg}$ twice daily or omeprazole $20 \mathrm{mg}$ once daily. Both ranitidine and omeprazole combinations were well tolerated and had no significant effect on the pharmacokinetics of darunavir/ritonavir.[18]

\section{Non-Nucleoside Reverse Transcriptase Inhibitors}

Two new NNRTIs, one recently approved and the other in phase III clinical development, have the potential for drug-drug interactions.

\subsection{Etravirine}

Etravirine (TMC125) is a second-generation NNRTI, which was recently approved by the FDA for treatment-experienced patients with resistance to an NNRTI and other antiretroviral agents (figure 1b). Etravirine, administered with or without a protease inhibitor or enfuvirtide, is the first NNRTI to show clinical efficacy after 24 weeks in patients who have demonstrated failure to respond to treatment with both a protease inhibitor and either nevirapine or efavirenz.[40]

2.1.1 Pharmacology-The molecular weight of etravirine is $435.277 \mathrm{~g} / \mathrm{mol} .[41]$ Etravirine is a highly flexible, diaryl pyrimidine (DAPY) compound. Its structural flexibility facilitates multiple binding complexes with both wild-type and mutant HIV strains, and thus it has a high genetic barrier to the development of resistance.[42] Etravirine is highly bound to human plasma proteins (>99\%).[43] It is predominantly metabolized by CYP3A4, CYP2C9 and CYP2C19, with minor glucuronidation.[44] Etravirine is a moderate inducer of CYP3A4 and acyl glucuronides and a moderate inhibitor of CYP2C9 and CYP2C19.[45] In vitro, etravirine metabolism is reduced by CYP3A4 inhibitors (i.e. indinavir) and is increased by CYP3A4 inducers (i.e. nevirapine).[46] Renal elimination of etravirine is minimal $(<1.2 \%)$.[47]

Four formulations of etravirine have been investigated in pharmaceutical clinical trials: TF002, TF034, TF035 and F060. Formulation TF035 was administered in most phase I and phase II trials. Formulation F060, with enhanced bioavailability, was introduced in phase IIV clinical trials and is now commercially available.[45]

2.1.2 Pharmacokinetics-Etravirine has a 30- to 40-hour systemic half-life and a distribution half-life of 3.9-5.4 hours.[47] The pharmacokinetic activity of etravirine (TF035) was evaluated in two phase I, 7-day randomized, crossover studies in healthy subjects. In the first study, 24 subjects ( 23 male, 1 female) were given etravirine $100 \mathrm{mg}$ twice daily, followed by etravirine $200 \mathrm{mg}$ once daily. The least square mean ratios comparing the pharmacokinetic parameters of once-daily and twice-daily administration 
were as follows: $\mathrm{C}_{\min } 0.74$ (90\% CI 0.69, 0.80), $\mathrm{C}_{\max } 1.42$ (90\% CI 1.34, 1.51) and $\mathrm{AUC}_{24}$ 1.05 (90\% CI 0.96, 1.14). In the second study, 41 subjects ( 22 male, 19 female) were given etravirine $200 \mathrm{mg}$ twice daily followed by etravirine $400 \mathrm{mg}$ once daily. The least square mean ratios comparing the pharmacokinetic parameters of once-daily and twice-daily administration were as follows: $\mathrm{C}_{\min } 0.75$ (90\% CI 0.72, 0.79), $\mathrm{C}_{\max } 1.44$ (90\% CI 1.37, 1.50) and $\mathrm{AUC}_{24} 1.03$ (90\% CI 1.00, 1.07). These results indicate that the $\mathrm{C}_{\min }$ of etravirine is $25-26 \%$ lower with a once-daily dosage regimen than with a twice-daily regimen, although equal daily administration results in similar overall daily systemic exposures.[48]

Etravirine exposure is reduced by 50\% when administered in a fasted state.[47] The effect of food and the type of meal on etravirine pharmacokinetics was investigated in a randomized, open-label, three-way, crossover trial in two groups of 12 healthy subjects. A $100 \mathrm{mg}$ dose of etravirine (F060) was administered under the following five conditions: fasting, a standardized low-fat breakfast, a snack, a high-fat meal and a high-fibre meal. Etravirine pharmacokinetics were evaluated over 96 hours. When administered with a standardized meal, the mean etravirine $\mathrm{AUC}_{12}$ values in the two groups were $1417 \pm 1140 \mathrm{ng} \bullet \mathrm{h} / \mathrm{mL}$ and $1191 \pm 700 \mathrm{ng} \bullet \mathrm{h} / \mathrm{mL}$. The mean $\mathrm{C}_{\max }$ values in the two groups were $129 \pm 64 \mathrm{ng} / \mathrm{mL}$ and $138 \pm 61 \mathrm{ng} / \mathrm{mL}$. Under fasting conditions, the $\mathrm{C}_{\max }$ and $\mathrm{AUC}_{12}$ of etravirine decreased by $44 \%$ and $51 \%$, respectively. With a high-fibre meal, the etravirine $\mathrm{C}_{\max }$ and $\mathrm{AUC}_{12}$ decreased by $25 \%$. Pharmacokinetic parameters were similar between the conditions in which subjects were provided with breakfast and either a high-fat meal or a snack. Therefore, it is recommended that etravirine should be administered with food.[49]

Finally, etravirine may be administered in patients with mild or moderate hepatic impairment without dose adjustment. In a study comparing the exposures of $200 \mathrm{mg}$ of etravirine administered twice daily in HIV-negative volunteers with mild (Child-Pugh Class $\mathrm{A}, \mathrm{n}=8$ ) or moderate (Child-Pugh Class $\mathrm{B}, \mathrm{n}=8$ ) hepatic impairment with healthy matched controls $(\mathrm{n}=16)$, etravirine exposures were comparable. After 8 days, the mean etravirine $\mathrm{AUC}_{12}$ value among volunteers with mild hepatic impairment was $9546 \pm 2630 \mathrm{ng} \bullet \mathrm{h} / \mathrm{mL}$, while the mean etravirine $\mathrm{AUC}_{12}$ value among matched healthy controls was $10650 \pm 1688$ $\mathrm{ng} \bullet \mathrm{h} / \mathrm{mL}$. After 8 days, the mean etravirine $\mathrm{AUC}_{12}$ value among volunteers with moderate hepatic impairment was $7665 \pm 4122 \mathrm{ng} \bullet \mathrm{h} / \mathrm{mL}$, while the mean etravirine $\mathrm{AUC}_{12}$ value among matched healthy controls was $8584 \pm 1560 \mathrm{ng} \bullet \mathrm{h} / \mathrm{mL}$.[50]

2.1.3 Drug-Drug Interactions-Drug-drug interaction data for etravirine are available for selected nucleoside reverse transcriptase inhibitors (NRTIs), NNRTIs, protease inhibitors and gastric acid-reducing agents. Sildenafil may require dose adjustment when administered in conjunction with etravirine. Efavirenz, nevirapine, tipranavir/ritonavir, fosamprenavir/ ritonavir, atazanavir/ritonavir, unboosted protease inhibitors and clarithromycin should not be coadministered.[25,46]

Etravirine and Protease Inhibitors: Etravirine decreases saquinavir exposure probably through induction of CYP3A4 enzyme activity. A single dose of saquinavir 1200mg given to 12 healthy subjects after 14 days of etravirine (TF035) $900 \mathrm{mg}$ twice daily resulted in the saquinavir AUC and $\mathrm{C}_{\max }$ being decreased by a mean of $52 \%(90 \% \mathrm{CI} 20,71)$ and $46 \%$ (90\% CI 14, 55), respectively.[51]

Full-dose ritonavir is known to both inhibit and induce CYP3A4 activity and to induce glucuronidation.[52] In a study of 11 healthy subjects, a single dose of etravirine (TF035) $400 \mathrm{mg}$ was administered after ritonavir $600 \mathrm{mg}$ twice daily for 7 days. Ritonavir significantly decreased the etravirine $\mathrm{AUC}_{12}$ by $46 \%$ (range 27-59\%) and the $\mathrm{C}_{\max }$ by $32 \%$ (range 15-45\%).[53] The observed decrease in etravirine exposure when administered with 
full-dose ritonavir provides evidence for glucuronidation as a second metabolic pathway for etravirine.[53] Full-dose ritonavir and etravirine should not be coadministered.[25]

When indinavir and etravirine are coadministered, indinavir concentrations decrease and etravirine concentrations increase. Ten healthy subjects were given indinavir $800 \mathrm{mg}$ three times daily with etravirine (TF035) $1600 \mathrm{mg}$ twice daily for 14 days. The GMRs for the etravirine $\mathrm{AUC}_{12}, \mathrm{C}_{\max }$ and $\mathrm{C}_{\min }$ comparing etravirine administered with indinavir and etravirine alone were $1.51(90 \%$ CI 1.20, 1.90), $1.51(90 \%$ CI 1.16, 1.97) and $1.52(90 \%$ CI $1.20,1.91)$, respectively. The GMRs for the indinavir $\mathrm{AUC}_{8}, \mathrm{C}_{\max }$ and $\mathrm{C}_{\min }$ comparing etravirine administered with indinavir and indinavir alone were 0.54 (90\% CI 0.46, 0.62), $0.72(90 \%$ CI 0.58, 0.89) and 0.24 (90\% CI 0.18, 0.34), respectively.[53] Based on these data, indinavir and etravirine should not be combined.

Unexpected drug interactions can occur with ritonavir-boosted protease inhibitors. Fosamprenavir alone has been shown to induce CYP3A4 enzyme activity, while low-dose ritonavir is a potent CYP3A4 inhibitor.[54] In a two-way, open-label, pharmacokinetic drug interaction study with eight HIV-infected patients, coadministration of etravirine, fosamprenavir and ritonavir was investigated. All patients were taking a stable regimen of fosamprenavir/ritonavir $700 \mathrm{mg} / 100 \mathrm{mg}$ twice daily. Etravirine (TF035) $800 \mathrm{mg}$ twice daily was added to the regimen for 14 days. With this combination, the $\mathrm{AUC}_{12}, \mathrm{C}_{\max }$ and $\mathrm{C}_{\min }$ of amprenavir increased by $69 \%, 62 \%$ and $77 \%$, respectively. The pharmacokinetic parameters of etravirine were similar to those observed in historical controls.[55] Coadministration of etravirine and fosamprenavir/ritonavir should be avoided. If concomitant use is required, patients should be monitored carefully for adverse events associated with increased amprenavir exposure, including nausea, vomiting, paraesthesias, elevated liver enzymes and neuropathy.[25]

Tipranavir administered without ritonavir induces CYP3A4 enzyme activity.[56] Tipranavir/ ritonavir has been found to potently inhibit hepatic and intestinal CYP3A4/5 enzyme activity after a single dose and to moderately induce hepatic and intestinal CYP3A4/5 enzyme activity over time. However, the net effect is CYP3A4/5 inhibition once steady-state conditions are achieved.[57] In a study of 24 healthy subjects, tipranavir/ritonavir $500 \mathrm{mg} /$ $200 \mathrm{mg}$ twice daily decreased the exposure of etravirine (TF035) $800 \mathrm{mg}$ twice daily by $76 \%$. The etravirine $\mathrm{AUC}_{12}, \mathrm{C}_{\max }$ and $\mathrm{C}_{\min }$, administered with tipranavir/ritonavir, declined by a mean of $76 \%$ (90\% CI 67, 82), 71\% (90\% CI 60, 78) and 82\% (90\% CI 75, 87), respectively. Etravirine slightly increased tipranavir exposure, with the $\mathrm{AUC}_{12}, \mathrm{C}_{\max }$ and $\mathrm{C}_{\min }$ increasing by a mean of $18 \%(90 \%$ CI 3,36$), 14 \%(90 \%$ CI 2,27$)$ and $24 \%(90 \% \mathrm{CI}$ $-4,59)$. Ritonavir exposures were similarly increased. Owing to the clinically significant decrease in etravirine exposure when administered with tipranavir/ritonavir, these two drugs should not be used in combination.[58]

Dual-boosted protease inhibitor therapy, once a management strategy of interest, has now fallen out of favour because of the complex drug interactions and lack of documented benefit compared with single-boosted protease inhibitor therapy. The pharmacokinetic influence of etravirine (TF035) $800 \mathrm{mg}$ twice daily was evaluated in $15 \mathrm{HIV}$-infected patients on a stable regimen of twice-daily lopinavir/ritonavir/saquinavir at varying dosages: $400 \mathrm{mg} / 100 \mathrm{mg} / 1000 \mathrm{mg}(\mathrm{n}=6), 400 \mathrm{mg} / 100 \mathrm{mg} / 800 \mathrm{mg}(\mathrm{n}=5), 400 \mathrm{mg} / 200 \mathrm{mg} / 800 \mathrm{mg}$ $(\mathrm{n}=1)$ and $533 \mathrm{mg} / 133 \mathrm{mg} / 800 \mathrm{mg}(\mathrm{n}=3)$. Pharmacokinetic treatment ratios comparing drug concentrations on etravirine with those off etravirine were computed in a combined analysis of subject data $(\mathrm{n}=11)$ from all dosage conditions. When combined with etravirine, the lopinavir $\mathrm{AUC}_{12}, \mathrm{C}_{\max }$ and $\mathrm{C}_{\min }$ were $82 \%, 84 \%$ and $76 \%$, respectively, of those without etravirine; the saquinavir $\mathrm{AUC}_{12}, \mathrm{C}_{\max }$ and $\mathrm{C}_{\min }$ were $87 \%, 85 \%$ and $87 \%$, respectively, of those without etravirine, and the ritonavir $\mathrm{AUC}_{12}, \mathrm{C}_{\max }$ and $\mathrm{C}_{\min }$ were $88 \%$, 
$89 \%$ and $87 \%$, respectively, of those without etravirine. Statistically significant decreases were noted only for the lopinavir $\mathrm{C}_{\max }(\mathrm{p}=0.03)$ and $\mathrm{AUC}_{12}(\mathrm{p}=0.04)$. However, with these observed changes being relatively small (11-24\%), clinical significance is unlikely. No clinically significant changes were observed in the pharmacokinetic parameters of saquinavir and ritonavir $(\mathrm{p}>0.3)$.[59]

Etravirine and Reverse Transcriptase Inhibitors: Only the NRTI didanosine has been evaluated in an interaction study with etravirine, with no clinically significant changes in the pharmacokinetics of either drug. Fourteen healthy subjects were given etravirine (TF035) $800 \mathrm{mg}$ twice daily with didanosine $400 \mathrm{mg}$ once daily.[60] For etravirine, the GMRs for the $\mathrm{AUC}_{12}, \mathrm{C}_{\max }$ and $\mathrm{C}_{\min }$ were 1.11 (90\% CI 0.98, 1.24), 1.16 (90\% CI 1.02, 1.32) and 1.04 ( $90 \%$ CI 0.93, 1.17), respectively. For didanosine, the GMRs for the $\mathrm{AUC}_{24}$ and $\mathrm{C}_{\max }$ were 0.99 (90\% CI 0.79, 1.25) and 0.91 (90\% CI 0.58, 1.42), respectively. These findings were confirmed in a study evaluating staggered administration of etravirine and didanosine.[61] Based on these data, no dose adjustments are recommended for this combination.

When administered with nevirapine or efavirenz, etravirine exposure significantly decreases. In a 14-day study of five healthy subjects, nevirapine $200 \mathrm{mg}$ twice daily reduced the $\mathrm{AUC}_{12}$ and $\mathrm{C}_{\max }$ of a single dose of etravirine (TF035) $900 \mathrm{mg}$ by $55 \%$ and $36 \%$, respectively.[51] In a larger study of 12 healthy subjects given efavirenz $600 \mathrm{mg}$ once daily for 14 days, etravirine exposure (the $\mathrm{C}_{\max }$ and $\mathrm{AUC}_{12}$ ) decreased by $18 \%$ and $40 \%$, respectively: the GMRs for the $\mathrm{C}_{\max }$ and $\mathrm{AUC}_{12}$ for a single dose of etravirine $900 \mathrm{mg}$ were 0.83 (90\% CI 0.73 0.93) and 0.59 (90\% CI 0.52, 0.68), respectively.[53] Since nevirapine and efavirenz are both substrates and inducers of CYP3A4/5 enzyme activity, it is anticipated that coadministration of these drugs with etravirine will result in either unchanged or reduced nevirapine and efavirenz exposures. Therefore, it is recommended that these drugs not be given in combination.[25]

A study evaluating the pharmacokinetics and safety of etravirine administered once or twice daily after multiple doses of efavirenz found that efavirenz-dependent CYP3A induction persists for at least 14 days after efavirenz is stopped. Healthy volunteers $(n=24,10$ females) received etravirine $400 \mathrm{mg}$ once daily or etravirine $200 \mathrm{mg}$ twice daily for 14 days, followed by 14 days of efavirenz $600 \mathrm{mg}$ once daily. After this time, each subject received their initial etravirine regimen for another 14 days. Full pharmacokinetic assessments before and after the 14-day administration of efavirenz indicated that etravirine exposure decreased in both treatment groups. The etravirine $\mathrm{C}_{\max }$ and $\mathrm{AUC}_{24}$ decreased by $22 \%$ and $32 \%$, respectively, in those receiving etravirine $400 \mathrm{mg}$ once daily. For those who took etravirine $200 \mathrm{mg}$ twice daily, the etravirine $\mathrm{C}_{\max }$ and $\mathrm{AUC}_{24}$ decreased by $19 \%$ and $26 \%$, respectively. Efavirenz concentrations were detectable in all subjects 7 days after the drug was stopped. The decrease in etravirine exposure was not considered clinically significant, and therefore no dosage adjustment is necessary when switching from efavirenz to etravirine.[62]

Etravirine and Integrase Inhibitors: Elvitegravir and raltegravir are members of the newest class of antiretroviral agents (see section 4), and they are metabolized by CYP3A4 (elvitegravir) and glucuronidase enzymes (elvitegravir and raltegravir). Elvitegravir is currently administered with ritonavir. An investigation into the pharmacokinetic interaction between elvitegravir/ritonavir $150 \mathrm{mg} / 100 \mathrm{mg}$ once daily and etravirine (F060) $200 \mathrm{mg}$ twice daily was conducted in a study of 34 healthy subjects ( 17 male, 17 female). No clinically relevant drug interactions were found between elvitegravir/ritonavir and etravirine. [43] 
Similarly, there is no interaction between etravirine and raltegravir, as determined in a crossover study of 19 healthy subjects. All subjects received raltegravir $400 \mathrm{mg}$ and etravirine (F060) $200 \mathrm{mg}$ twice daily. Raltegravir minimally increased the $\mathrm{AUC}_{12}, \mathrm{C}_{\max }$ and $\mathrm{C}_{\min }$ of etravirine by $10 \%, 4 \%$ and $17 \%$, respectively. Etravirine decreased the $\mathrm{AUC}_{12}$, $\mathrm{C}_{\max }$ and $\mathrm{C}_{\min }$ of raltegravir by $10 \%, 11 \%$ and $34 \%$, respectively. The observed small decreases in the pharmacokinetic parameters of raltegravir may stem from the induction of glucuronidation by etravirine.[63]

Etravirine and Phosphodiesterase 5 Inhibitors: Fifteen healthy subjects were given a single dose of sildenafil $50 \mathrm{mg}$ after 13 days of etravirine (TF035) $800 \mathrm{mg}$ twice daily.[44] The mean decline in the sildenafil $\mathrm{AUC}_{12}$ was $57 \%$ (range 49-64\%), suggesting that etravirine induction of CYP3A4 reduced these concentrations. Therefore, it is advised that the dose of sildenafil be increased and titrated according to the clinical effect when coadministered with etravirine.

Etravirine and Selective Serotonin Reuptake Inhibitors: No dose adjustment is required when etravirine and paroxetine are administered together. This interaction was studied in 16 healthy subjects given etravirine (TF035) $125 \mathrm{mg}$ twice daily and paroxetine $20 \mathrm{mg}$ once daily. Minimal changes were observed in the pharmacokinetic parameters of both drugs. Etravirine increased the $\mathrm{AUC}_{12}$ and $\mathrm{C}_{\max }$ of paroxetine by $3 \%$ and $6 \%$, respectively. Paroxetine increased the $\mathrm{AUC}_{12}, \mathrm{C}_{\max }$ and $\mathrm{C}_{\min }$ of etravirine by $1 \%, 5 \%$ and $7 \%$, respectively.[64]

Etravirine and Acid-Reducing Agents: Acid-reducing agents do not affect the pharmacokinetics of etravirine to a clinically significant extent. In a study of 19 healthy subjects (12 male, 7 female) given ranitidine $150 \mathrm{mg}$ twice daily and a single dose of etravirine (F060) $100 \mathrm{mg}$, no change was noted in the $\mathrm{AUC}_{12}$ (GMR 0.86; $90 \% \mathrm{CI} 0.76$, 0.97 ) or $\mathrm{C}_{\max }$ (GMR $0.94 ; 90 \%$ CI $0.75,1.17$ ) of etravirine. In a study of 19 healthy subjects given omeprazole $40 \mathrm{mg}$ once daily and a single dose of etravirine $100 \mathrm{mg}$, the $\mathrm{AUC}_{12}$ and $\mathrm{C}_{\max }$ of etravirine increased by a mean of $41 \%$ (range $22-62 \%$ ) and $17 \%$ (range $0-43 \%$ ), respectively.[65] This interaction is likely to be due to competitive inhibition of CYP2C19. However, no dosage adjustment is required to accommodate this interaction.

Etravirine and Methadone: Methadone is a racemic mixture of two enantiomers, $R$ methadone and $S$-methadone. $S$-methadone is pharmacologically inactive and is more protein bound than $R$-methadone. $R$-methadone is pharmacologically active and displays a greater mean plasma clearance, volume of distribution and mean elimination half-life than $S$ methadone.[66] Methadone undergoes stereoselective hepatic metabolism primarily by CYP2B6 and is also metabolized to a much lesser extent by CYP3A4.[67] In an open-label study of 16 healthy male subjects on stable therapy with methadone, etravirine (F060) 100 $\mathrm{mg}$ was administered twice daily for 14 days. No clinically significant changes in methadone exposure were observed. For R-methadone administered alone, the (mean $\pm \mathrm{SD}$ ) $\mathrm{C}_{\max }$ was $222 \pm 74 \mathrm{ng} / \mathrm{mL}$ and the $\mathrm{AUC}_{24}$ was $3807 \pm 1301 \mathrm{ng} \bullet \mathrm{h} / \mathrm{mL}$. After 14 days of coadministration with $100 \mathrm{mg}$ of etravirine twice daily, the $\mathrm{C}_{\max }$ of $R$-methadone was $228 \pm$ $75 \mathrm{ng} / \mathrm{mL}$ and the $\mathrm{AUC}_{24}$ was $4038 \pm 1309 \mathrm{ng} \bullet \mathrm{h} / \mathrm{mL}$. For $S$-methadone administered alone, the $\mathrm{C}_{\max }$ was $285 \pm 103 \mathrm{ng} / \mathrm{mL}$ and the $\mathrm{AUC}_{24}$ was $4378 \pm 1809 \mathrm{ng} \bullet \mathrm{h} / \mathrm{mL}$. After 14 days of the coadministration with $100 \mathrm{mg}$ of etravirine twice daily, the $\mathrm{C}_{\max }$ of $S$-methadone was $264 \pm 107 \mathrm{ng} / \mathrm{mL}$ and the $\mathrm{AUC}_{24}$ was $4029 \pm 1834 \mathrm{ng} \bullet \mathrm{h} / \mathrm{mL}$.[68]

No methadone withdrawal symptoms were observed. However, owing to the long elimination half-life of methadone (7-59 hours), 14 days of therapy may not be of sufficient duration to see an effect. Given these results, methadone dose adjustment is not necessary 
when coadministered with etravirine.[69] However, patients should be monitored for withdrawal symptoms, and some patients may require a dose adjustment for methadone.[25]

Etravirine and Anti-Infectives: Clarithromycin inhibits CYP3A4 and is also converted by CYP3A4 to its active metabolite, 14-hydroxy-clarithromycin. Etravirine is a substrate and inducer of CYP3A4. Sixteen healthy male subjects participated in a randomized, open-label, two-period, crossover trial in which the pharmacokinetics of etravirine $200 \mathrm{mg}$ twice daily were investigated alone and in combination with clarithromycin $500 \mathrm{mg}$ twice daily. The overall exposure of clarithromycin decreased in the presence of etravirine, while concentrations of its metabolite, 14-hydroxy-clarithromycin, increased. Etravirine exposure increased as well. The least square mean ratios for the pharmacokinetic parameters of etravirine administered in combination with clarithromycin compared with etravirine alone were $\mathrm{AUC}_{12} 142 \%$ (90\% CI 134, 150), $\mathrm{C}_{\max } 146 \%\left(90 \%\right.$ CI 138, 156) and $\mathrm{C}_{\min } 146 \%$ (90\% CI 136, 158). The least square mean ratios for the pharmacokinetic parameters of 14hydroxy-clarithromycin when clarithromycin was administered in combination with etravirine compared with etravirine alone were $121 \%\left(90 \%\right.$ CI 105, 139) for the $\mathrm{AUC}_{12}$, $133 \%\left(90 \%\right.$ CI 113, 156) for the $\mathrm{C}_{\max }$ and $105 \%\left(90 \%\right.$ CI 90,122) for the $\mathrm{C}_{\min }$. Since 14hydroxy-clarithromycin has reduced activity against Mycobacterium avium complex, overall activity against these organisms may be affected, and it is recommended that an alternative agent, such as azithromycin, be considered.[70]

Etravirine and Antimycobacterials: Rifampicin, a potent inducer of CYP enzymes, is not recommended for use with etravirine. Although no study has been conducted to specifically investigate this interaction, it is likely that rifampicin will cause a significant decrease in etravirine exposure.[25]

Both etravirine and rifabutin are substrates and inducers of CYP3A4 enzyme activity. Rifabutin is commonly used as prophylaxis against Mycobacterium avium complex disease in patients with advanced HIV disease. The 24-hour pharmacokinetic profiles of rifabutin and its active metabolite, 25- $O$-desacetyl rifabutin, were examined in the presence of etravirine. In this open-label, randomized, two-period, crossover trial, 16 healthy HIVnegative subjects took rifabutin $300 \mathrm{mg}$ once daily for 14 days followed by a 14-day washout period. Following the washout period, each subject took etravirine (TF035) $800 \mathrm{mg}$ twice daily for 7 days followed by the combination of etravirine (TF035) $800 \mathrm{mg}$ twice daily and rifabutin $300 \mathrm{mg}$ once daily for 14 days. In the 11 subjects included in the final analysis, steady-state exposures of the etravirine concentration at 12 hours $\left(\mathrm{C}_{12}\right)$ decreased by approximately $37 \%$. These effects are comparable to the decrease in etravirine when coadministered with protease inhibitors. Steady-state exposures of rifabutin and 25-Odesacetyl rifabutin at 24 hours postdose declined by approximately $17 \%$ when coadministered with etravirine. Since these effects are not considered to be clinically relevant, rifabutin may be administered in conjunction with etravirine without dose adjustment.[71]

Etravirine and Azole Antifungals: Formal studies have not been conducted to elucidate the effects of etravirine coadministration. Based upon known pharmacological properties of etravirine and fluconazole, coadministration of these two agents is not expected to significantly affect the exposure of either drug. Based upon the known properties of ketoconazole and itraconazole, it is anticipated that if either agent is coadministered with etravirine, the plasma concentrations of etravirine will decrease and the concentration of either ketoconazole or itraconazole will decrease. These azole antifungals should be used with caution in a patient who is taking etravirine and may require a dose adjustment, depending on other drugs in the patient's medication regimen.[25] 
Etravirine and HMG-CoA Reductase Inhibitors: Atorvastatin is primarily metabolized by CYP3A4. Sixteen healthy subjects participated in a randomized, open-label, two-period, crossover trial aimed at characterizing the pharmacokinetic parameters of etravirine (TF035) $800 \mathrm{mg}$ twice daily in conjunction with atorvastatin $40 \mathrm{mg}$ once daily. Etravirine exposure was not affected by the presence of atorvastatin. The overall exposure of atorvastatin was decreased by $37 \%$ in the presence of etravirine and a $27 \%$ increase in the exposure of atorvastatin's active metabolite, 2-hydroxy-atorvastatin, was observed. The least square mean ratios for the pharmacokinetic parameters of atorvastatin administered in combination with etravirine compared with atorvastatin alone were $63 \%\left(90 \%\right.$ CI 58, 68) for the $\mathrm{AUC}_{24}$ and $104 \%(90 \% \mathrm{CI} 84,130)$ for the $\mathrm{C}_{\max }$. The least square mean ratios for the pharmacokinetic parameters of 2-hydroxy-atorvastatin when atorvastatin was administered in combination with etravirine compared with atorvastatin alone were 127\% (90\% CI 119, 136) for the $\mathrm{AUC}_{24}$ and $175 \%(90 \% \mathrm{CI} 160,194)$ for the $\mathrm{C}_{\max .[72]}$

\subsection{Rilpivirine}

Rilpivirine (TMC278) is a diarylpyrimidine compound with a higher genetic barrier to resistance compared with currently approved NNRTIs. This high genetic barrier may be due in part to its internal flexibility, enabling it to adjust its configuration in HIV-1 reverse transcriptase in the presence of mutations (figure 1c).

2.2.1 Pharmacology-The molecular weight of rilpivirine is $366.4 \mathrm{~g} / \mathrm{mol}$.[73] The $\mathrm{EC}_{50}$ of rilpivirine against wild-type $\mathrm{HIV}-1$ strains is $0.5 \mathrm{nmol} / \mathrm{L}(0.19 \mathrm{ng} / \mathrm{mL})$. Rilpivirine is a substrate of CYP3A4 enzyme activity and is slowly metabolized in human hepatocytes through glutathione-dependent conjugative metabolism. Rilpivirine is over $99 \%$ bound to human plasma proteins in a concentration-dependent manner.[74]

2.2.2 Pharmacokinetics-Pharmacokinetic parameters of rilpivirine were examined in a randomized, double-blind, placebo-controlled, dose-ranging study in antiretroviral-naïve, HIV-infected, men. Forty-seven patients received rilpivirine 25 to $150 \mathrm{mg}$ as monotherapy for 7 days. Full pharmacokinetic profiles completed on days 1 and 7 indicated that rilpivirine was rapidly and well absorbed. The $\mathrm{C}_{\max }$ was attained by 3-4 hours, and the terminal elimination half-life was estimated at 48 hours. After 7 days of a $50 \mathrm{mg}$ dose, the mean $\pm \mathrm{SD}$ $\mathrm{C}_{\max }$ was $366 \pm 125 \mathrm{ng} / \mathrm{mL}$ and the $\mathrm{AUC}_{24}$ was $4904 \pm 1677 \mathrm{ng} \bullet \mathrm{h} / \mathrm{mL}$. With a $100 \mathrm{mg}$ dose, the mean $\pm \mathrm{SD} \mathrm{C}_{\max }$ was $712 \pm 351 \mathrm{ng} / \mathrm{mL}$ and the $\mathrm{AUC}_{24}$ was $9517 \pm 4397 \mathrm{ng} \bullet \mathrm{h} /$ $\mathrm{mL}$. Plasma concentrations increased with increasing doses of rilpivirine but were not dose proportional. The $75 \mathrm{mg}$ dose of rilpivirine was selected for development and is being evaluated in phase III clinical trials. The plasma concentrations obtained with this dose are above the target concentration of $13.5 \mathrm{ng} / \mathrm{mL}$, the $\mathrm{EC}_{50}$ for wild-type virus adjusted for protein binding.[75]

Rilpivirine should be administered with food. A study of rilpivirine $100 \mathrm{mg}$ in 12 healthy Caucasian men found that under fed conditions, the $\mathrm{C}_{\max }$ of rilpivirine is approximately $71 \%$ higher and the $\mathrm{AUC}$ from 0 to 48 hours $\left(\mathrm{AUC}_{48}\right)$ is approximately $45 \%$ higher compared with concentrations observed in a fasted state.[76]

\subsubsection{Drug-Drug Interactions}

Rilpivirine and Protease Inhibitors: Rilpivirine $150 \mathrm{mg}$ once daily and darunavir/ritonavir $800 \mathrm{mg} / 100 \mathrm{mg}$ once daily were coadministered in 16 healthy subjects. Darunavir/ritonavir increased the $\mathrm{AUC}_{24}, \mathrm{C}_{\max }$ and $\mathrm{C}_{\min }$ of rilpivirine by $230 \%, 79 \%$ and $278 \%$, respectively. Rilpivirine had no clinically relevant effect on darunavir/ritonavir exposure. It is likely that the increase in rilpivirine exposure is a result of CYP3A4 inhibition.[77] Specific dose 
recommendations for coadministration of rilpivirine and darunavir have yet to be determined. No data combining rilpivirine with other protease inhibitors are available.

Rilpivirine and Reverse Transcriptase Inhibitors: Fifteen healthy subjects participated in a study evaluating the steady-state interaction between once-daily administration of rilpivirine $150 \mathrm{mg}$ and tenofovir $300 \mathrm{mg}$. Tenofovir had no effect on the pharmacokinetics of rilpivirine (a mean $2 \%$ increase in the $\mathrm{AUC}_{24}$, a $3 \%$ decrease in the $\mathrm{C}_{\max }$ and no change in the $\mathrm{C}_{\min }$ ). However, tenofovir exposure was increased in the presence of rilpivirine, with a mean $24 \%$ increase in the $\mathrm{AUC}_{24}$, a $21 \%$ increase in the $\mathrm{C}_{\max }$ and a $21 \%$ increase in the $\mathrm{C}_{\mathrm{min}}$. [78] Although the effect of rilpivirine on tenofovir exposure is statistically significant, it is not considered clinically relevant, and no dose modifications are recommended.

Rilpivirine and HMG-CoA Reductase Inhibitors: Atorvastatin $40 \mathrm{mg}$ once daily had no significant effect on the pharmacokinetics of rilpivirine ( $150 \mathrm{mg}$ once daily) in a study of 16 healthy subjects. However, rilpivirine increased the $\mathrm{C}_{\max }$ of atorvastatin by $35 \%$, but did not change the $\mathrm{AUC}_{24}$ or $\mathrm{C}_{\mathrm{min}}$. The $\mathrm{AUC}_{24}$ of the 2-hydroxy and 4-hydroxy metabolites of atorvastatin also increased by $39 \%$ and $23 \%$, respectively. Overall, the AUC of total HMGCoA reductase activity (calculated by the AUC sum of atorvastatin with the two metabolites) increased by $20 \%$.[79] Therefore, no dose reduction in atorvastatin is necessary with concomitant rilpivirine therapy.

Rilpivirine and Anti-Infectives: The pharmacological effect of administration of rilpivirine and anti-infectives has yet to be determined in clinical studies.

Rilpivirine and Azole Antifungals: The pharmacokinetic interaction between rilpivirine $150 \mathrm{mg}$ once daily and ketoconazole $400 \mathrm{mg}$ once daily was examined in a study of 16 healthy subjects. In the presence of ketoconazole, the $\mathrm{AUC}_{24}, \mathrm{C}_{\max }$ and $\mathrm{C}_{\min }$ of rilpivirine increased by a mean of $49 \%, 30 \%$ and $76 \%$, respectively. In the presence of rilpivirine, the $\mathrm{AUC}_{24}, \mathrm{C}_{\max }$ and $\mathrm{C}_{\min }$ of ketoconazole decreased by a mean of $24 \%, 15 \%$ and $66 \%$. Specific dosage recommendations for coadministration of these medications have yet to be formulated, but it is clear that this should be diligently monitored.[80]

Rilpivirine and Antimycobacterials: Rifampicin, a potent inducer of CYP3A4, is not recommended for use with rilpivirine. A study of the coadministration of rilpivirine and rifampicin in 16 healthy, HIV-negative subjects found that the AUC and $\mathrm{C}_{\min }$ of rilpivirine were reduced by $80 \%$ and $89 \%$, respectively, over a 24 -hour period in the presence of rifampicin. Rifampicin exposure was not changed.[81]

Rilpivirine and Acid-Reducing Agents: Since the solubility of rilpivirine decreases in solutions with increasing $\mathrm{pH}$, coadministration of drugs that increase gastric $\mathrm{pH}$ may influence its absorption. A randomized, single-dose, four-way, crossover trial was conducted to examine the pharmacokinetic effect of coadministration of rilpivirine and famotidine, a commonly used $\mathrm{H}_{2}$-receptor antagonist. Twenty-four healthy male subjects completed four treatment conditions, each separated by a 14-day washout period. Rilpivirine $150 \mathrm{mg}$ was administered alone and with famotidine $40 \mathrm{mg}$ given 2 hours before, 12 hours before or 4 hours after a single dose of rilpivirine $150 \mathrm{mg}$ with food. Intragastric $\mathrm{pH}$ was measured for 24 hours, and the pharmacokinetics of famotidine and rilpivirine were assessed up to 24 and 168 hours after the dose, respectively. When famotidine was given 2 hours beforehand, the rilpivirine $\mathrm{C}_{\max }$ and the AUC from time zero to infinity $\left(\mathrm{AUC}_{\infty}\right)$ were reduced by $85 \%$ and $76 \%$, respectively, in comparison with when rilpivirine was administered alone. This interaction is suspected to result from the reduced solubility of rilpivirine with increased gastric $\mathrm{pH}$ levels. When famotidine was given 12 hours beforehand, or 4 hours afterwards, rilpivirine pharmacokinetics were not significantly affected. Famotidine pharmacokinetics 
were not affected by rilpivirine with any dosing strategy. Based on these findings, famotidine can be combined with rilpivirine, provided it is given 12 hours before or 4 hours after the rilpivirine dose.[82]

\section{Chemokine Receptor Antagonists}

\subsection{Maraviroc}

Maraviroc is a first-in-class CCR5-receptor antagonist approved by the FDA in August 2007 for use in treatment-experienced patients with drug resistance to multiple antiretrovirals. Maraviroc prevents HIV-1 entry by blocking coreceptor binding via reversible noncompetitive inhibition and preventing further fusion to host CD4+ cell membranes (figure 1d).

3.1.1 Pharmacology-The molecular weight of maraviroc is $513.67 \mathrm{~g} / \mathrm{mol}$.[83] The geometric mean $\mathrm{IC}_{90}$ for wild-type HIV-1 is $2.0 \mathrm{nmol} / \mathrm{L}$. This $\mathrm{IC}_{90}$ was determined in PBMC replication assays using viral clades A, B, C, D, E, F, G, J and O, with geometric means of the $\mathrm{IC}_{90}$ values ranging from 0.51 to $4.4 \mathrm{nmol} / \mathrm{L}$. Maraviroc is approximately $75 \%$ bound to albumin and $\alpha_{1}$-acid glycoprotein.[84]

Maraviroc is primarily metabolized by CYP3A4 and its metabolism is inhibited by approximately $70 \%$ in vitro when combined with potent CYP3A4 inhibitors such as ketoconazole. Metabolism of maraviroc is not altered in the presence of CYP2C9 (sulphaphenazole) or CYP2D6 (quinidine) inhibitors.[85] As the $\mathrm{IC}_{50}$ of maraviroc is greater than $30 \mu \mathrm{mol} / \mathrm{L}$, it has limited inhibitory potential for the following enzymes: CYP3A4, CYP2B6, CYP2D6, CYP2C8, CYP2C9, CYP2C19 and CYP1A2.[85] In healthy subjects, maraviroc does not affect the pharmacokinetics of cortisol or midazolam, two CYP3A4 substrates. A dose-ranging study of maraviroc $(25 \mathrm{mg}$ twice daily to $600 \mathrm{mg}$ once daily) demonstrated no change in $6 \beta$-hydroxycortisol/cortisol urinary ratios in 51 healthy subjects.[86] Maraviroc $300 \mathrm{mg}$ twice daily for 7 days increased the AUC and $\mathrm{C}_{\max }$ of oral midazolam by $<20 \%$, suggesting no clinically relevant interaction.[86,87]

Maraviroc also has high affinity for the efflux transporter P-glycoprotein (Michaelis-Menten constant $\left[\mathrm{K}_{\mathrm{m}}\right]=37 \mu \mathrm{mol} / \mathrm{L}$ ). Caco-2 permeability studies demonstrated polarized transport of maraviroc with an efflux ratio (basolateral $\rightarrow$ apical/apical $\rightarrow$ basolateral) of $>10$. This high efflux ratio suggests that an inhibitor of efflux could significantly enhance the absorption of maraviroc. For example, digoxin has also been reported to have an efflux ratio of 10 , and this ratio is reduced in the presence of known P-glycoprotein inhibitors such as verapamil (50\%) and CP-100356 (75\%). P-glycoprotein inhibitors, therefore, would have the potential to increase the absorption of maraviroc.[88]

3.1.2 Pharmacokinetics-Largely owing to enterocyte metabolism by CYP3A4 and efflux by P-glycoprotein, the dose-dependent bioavailability of maraviroc is $23-33 \%$. [89-91] In healthy subjects, the volume of distribution of maraviroc is $2.8 \mathrm{~L} / \mathrm{kg}$, and apparent oral clearance is $10.5 \mathrm{~mL} / \mathrm{min} / \mathrm{kg}$. The $t_{\max }$ ranges from 0.5 to 4 hours and the terminal elimination half-life from 14 to 18 hours. The pharmacokinetic parameters in HIVinfected patients are similar to those in healthy subjects. In addition to hepatic metabolism, renal clearance accounts for approximately $20-25 \%$ of the elimination of maraviroc. $[89,90,92,93]$

No sex or ethnicity (Caucasian vs Asian males) differences have been found in the pharmacokinetics of maraviroc.[90,94] In patients with mild and moderate liver impairment (Child-Pugh class A and B, respectively), the single-dose maraviroc AUC increased by $25 \%$ and $46 \%$, and the $\mathrm{C}_{\max }$ was increased by $11 \%$ and $32 \%$, respectively. However, it is unlikely 
that these changes will warrant an adjustment in dosage.[95] Caution is advised for using maraviroc in mild or moderate liver impairment. Pharmacokinetic evaluations have not yet been conducted in patients with severe hepatic impairment or renal impairment, or in pregnant, elderly or paediatric populations.[90]

Compared with the fasted state, high-fat meals reduce maraviroc exposure by $33 \%$, and lowfat meals reduce maraviroc exposure by $20 \%$. However, this does not appear to significantly affect antiviral activity, as no diet restrictions were made in phase III trials demonstrating safety and efficacy.[89,90]

3.1.3 Drug-Drug Interactions-As maraviroc is metabolized byCYP3A4 and transported by P-glycoprotein, dosage adjustment is required when CYP3A4 and/or Pglycoprotein inhibitors or inducers are administered concomitantly. The maraviroc dose should be reduced when combined with lopinavir, saquinavir, atazanavir and ritonavirboosted elvitegravir, and increased when combined with efavirenz and etravirine. The investigators for the following drug interaction studies did not report the effect of maraviroc on the concomitant regimen unless indicated otherwise.

Maraviroc and Protease Inhibitors: In an investigation of maraviroc pharmacokinetics in five HIV-infected subjects taking lopinavir/ritonavir $400 \mathrm{mg} / 100 \mathrm{mg}$ twice daily, stavudine $40 \mathrm{mg}$ twice daily, and lamivudine $150 \mathrm{mg}$ twice daily, a single dose of maraviroc $300 \mathrm{mg}$ was administered. Comparing the pharmacokinetic data with the day 1 data from a historic control of HIV-infected subjects, the maraviroc GMRs for the $\mathrm{AUC}_{12}$ and $\mathrm{C}_{\max }$ were 2.65 (90\% CI 1.61, 4.35) and 1.80 (90\% CI 1.03, 3.14). Therefore, a dose reduction strategy of maraviroc to $150 \mathrm{mg}$ twice daily is necessary when administered with lopinavir/ritonavir. $[96,97]$

In 12 healthy male subjects, maraviroc $100 \mathrm{mg}$ given twice daily combined with saquinavir $1200 \mathrm{mg}$ three times daily yielded maraviroc GMRs for the $\mathrm{AUC}_{12}$ and $\mathrm{C}_{\max }$ of 4.25 (90\% CI $3.47,5.19)$ and $3.32(90 \%$ CI $2.45,4.49)$, respectively.[98,99] Therefore, maraviroc dosing should be reduced from $300 \mathrm{mg}$ twice daily to $150 \mathrm{mg}$ twice daily in combination with unboosted saquinavir.

Healthy subjects were recruited to study the combined effects of CYP3A4 inhibitors and inducers on the pharmacokinetics of maraviroc. The combination of maraviroc $300 \mathrm{mg}$ twice daily with lopinavir/ritonavir $400 \mathrm{mg} / 100 \mathrm{mg}$ twice daily increased maraviroc exposure in 11 subjects: the GMRs for the maraviroc $\mathrm{AUC}_{12}$ and $\mathrm{C}_{\max }$ were 3.95 (90\% CI 3.43, 4.56) and 1.97 (90\% CI 1.66, 2.34), respectively. When efavirenz $600 \mathrm{mg}$ once daily was added to this regimen, the GMRs for the maraviroc $\mathrm{AUC}_{12}$ and $\mathrm{C}_{\max }$ were 2.53 (90\% CI 2.24, 2.87) and 1.25 (90\% CI 1.01, 1.55), respectively. The combination of maraviroc $100 \mathrm{mg}$ twice daily with saquinavir/ritonavir $1000 \mathrm{mg} / 100 \mathrm{mg}$ twice daily increased maraviroc exposure in healthy subjects: the maraviroc GMRs for the $\mathrm{AUC}_{12}$ and $\mathrm{C}_{\max }$ were 9.77 (90\% CI 7.87, 12.14 ) and 4.78 (90\% CI 3.41, 6.71), respectively. When efavirenz $600 \mathrm{mg}$ was added to this regimen, the maraviroc GMRs for the $\mathrm{AUC}_{12}$ and $\mathrm{C}_{\max }$ were 5.00 (90\% CI 4.26, 5.87) and 2.26 (90\% CI 1.64, 3.11), respectively.[90,100,101] Therefore, the maraviroc dose should be reduced when combined with lopinavir/ritonavir or saquinavir/ritonavir, including regimens that contain efavirenz.

A dose-adjustment trial demonstrated that a $75 \%$ reduction (from $100 \mathrm{mg}$ to $25 \mathrm{mg}$ ) in the maraviroc dose with saquinavir/ritonavir still resulted in a $40 \%$ increase in the AUC compared with maraviroc $100 \mathrm{mg}$ twice daily alone. However, reducing the dose of maraviroc to $25 \mathrm{mg}$ resulted in a $40 \%$ reduction in the $\mathrm{C}_{\max }$ compared with maraviroc 100 $\mathrm{mg}$ alone. Since the smallest dosage size for maraviroc is $150 \mathrm{mg}$ as an unscored, film- 
coated tablet (with no recommendations for splitting or crushing), and the dose-limiting toxicities for maraviroc appear to be related to the $\mathrm{C}_{\max }$ rather than the AUC, reducing the dose of maraviroc to $150 \mathrm{mg}$ twice daily is reasonable. When combining maraviroc with saquinavir/ritonavir, close monitoring of the adverse effects and toxicity of maraviroc is advised.[99]

In a two-way crossover study with tipranavir/ritonavir $500 \mathrm{mg} / 200 \mathrm{mg}$ twice daily, maraviroc $150 \mathrm{mg}$ twice daily resulted in GMRs for the $\mathrm{AUC}_{12}$ and $\mathrm{C}_{\max }$ of 1.02 (90\% CI $0.85,1.23)$ and $0.86(90 \%$ CI $0.61,1.21)$, respectively, suggesting no significant interaction. $[99,102]$ Thus, a standard dosage of maraviroc (300 mg twice daily) should be used when coadministered with tipranavir/ritonavir.

The interaction between maraviroc and atazanavir with or without ritonavir was studied in 12 healthy subjects. Maraviroc $300 \mathrm{mg}$ twice daily was given with either atazanavir $400 \mathrm{mg}$ once daily or atazanavir/ritonavir $300 \mathrm{mg} / 100 \mathrm{mg}$ once daily. When combined with atazanavir alone, the GMRs for the $\mathrm{AUC}_{12}$ and $\mathrm{C}_{\max }$ of maraviroc were 3.57 (90\% CI 3.30, 3.87 ) and 2.09 (90\% CI 1.72, 2.55), respectively, and with atazanavir/ritonavir they were 4.88 (90\% CI 4.40, 5.41) and 2.67 (90\% CI 2.32, 3.08), respectively.[90,99,103] Therefore, the maraviroc dose should be reduced to $150 \mathrm{mg}$ twice daily when combined with any atazanavir therapy.

Maraviroc and Reverse Transcriptase Inhibitors: The effect of maraviroc $300 \mathrm{mg}$ on lamivudine ( $150 \mathrm{mg}$ twice daily) or zidovudine ( $300 \mathrm{mg}$ twice daily) was evaluated in 11 healthy subjects. The GMRs for the lamivudine $\mathrm{AUC}_{12}$ and $\mathrm{C}_{\max }$ were 1.14 (90\% CI 0.984, 1.323 ) and 1.16 (90\% CI 0.875, 1.542), respectively. The GMRs for the zidovudine $\mathrm{AUC}_{12}$ and $\mathrm{C}_{\max }$ were $0.98(90 \% \mathrm{CI} 0.79,1.22)$ and $0.92(90 \%$ CI $0.68,1.24)$, respectively, for zidovudine. Therefore, no dosage adjustment is required when maraviroc is combined with zidovudine and lamivudine.[87,104]

To investigate the effects of efavirenz on maraviroc pharmacokinetics, 12 healthy subjects were given maraviroc $100 \mathrm{mg}$ twice daily with efavirenz $600 \mathrm{mg}$ once daily. The $\mathrm{AUC}_{12}$ and $\mathrm{C}_{\max }$ GMRs for maraviroc during efavirenz therapy were 0.487 (90\% CI $0.414,0.573$ ) and 0.436 (90\% CI 0.304, 0.624), respectively. When the dose of maraviroc was increased to $200 \mathrm{mg}$ twice daily, the GMRs for the $\mathrm{AUC}_{12}$ and $\mathrm{C}_{\max }$ were 1.09 (90\% CI $0.868,1.37$ ) and 1.16 (90\% CI $0.774,1.75)$, respectively. This study demonstrated that the effects of enzyme induction on maraviroc pharmacokinetics can be overcome by doubling the dose. $[101,105]$

In HIV-infected subjects, the GMRs for the maraviroc $\mathrm{AUC}_{12}$ and $\mathrm{C}_{\max }$ were 0.469 (90\% CI $0.303,0.724)$ and $0.665(90 \%$ CI $0.408,1.09)$, respectively, for those taking efavirenz with lamivudine/zidovudine $(\mathrm{n}=8)$ and $0.483(90 \%$ CI $0.313,0.746)$ and $0.764(90 \%$ CI $0.468,1.25)$, respectively, for those taking efavirenz with didanosine/tenofovir $(n=8)$. The maraviroc GMRs of the $\mathrm{AUC}_{12}$ and $\mathrm{C}_{\max }$ for those taking nevirapine (with lamivudine and tenofovir) were $1.01(90 \% \mathrm{CI} 0.651,1.55)$ and 1.54 (90\% CI 0.943, 2.51), respectively. These data confirm the interaction seen in healthy subjects, and the maraviroc dosage should be increased to $600 \mathrm{mg}$ twice daily when combined with efavirenz, but a standard dosage can be used when combined with nevirapine.[96,97]

In a two-period crossover study of the effects of etravirine with or without darunavir/ ritonavir on the pharmacokinetics of maraviroc, healthy subjects were enrolled. Etravirine was administered $200 \mathrm{mg}$ twice daily, maraviroc $150 \mathrm{mg}$ twice daily and darunavir/ritonavir $600 \mathrm{mg} / 100 \mathrm{mg}$ twice daily. Etravirine alone decreased the maraviroc $\mathrm{AUC}_{12}$ and $\mathrm{C}_{\max }$ by $53 \%$ and $60 \%$, respectively, while the combination of etravirine and darunavir/ritonavir 
increased the maraviroc $\mathrm{AUC}_{12}$ and $\mathrm{C}_{\max }$ by $210 \%$ and $77 \%$, respectively.[106] Therefore, an increase in the maraviroc dose is required when combined with etravirine alone, but it may not be necessary if there are other components of the medication regimen that inhibit maraviroc metabolism.

Maraviroc and Integrase Inhibitors: In a study of 36 healthy subjects, the combination of elvitegravir/ritonavir $150 \mathrm{mg} / 100 \mathrm{mg}$ with maraviroc $150 \mathrm{mg}$ did not affect concentrations of elvitegravir (the GMRs for the $\mathrm{AUC}_{12}$ and $\mathrm{C}_{\max }$ were 1.1 and 0.99 , respectively) or ritonavir (the GMRs for the $\mathrm{AUC}_{12}$ and $\mathrm{C}_{\max }$ were 0.98 and 0.92 , respectively). However, maraviroc concentrations increased: the GMRs for the $\mathrm{AUC}_{12}$ and $\mathrm{C}_{\max }$ were $2.86(90 \% \mathrm{CI}$ $2.33,3.51)$ and 2.15 (90\% CI 1.71, 2.69), respectively.[107] The combination of ritonavirboosted elvitegravir will require a 50\% dose reduction in maraviroc, which is similar to other ritonavir-containing regimens.

A phase IV trial in 18 healthy subjects (16 males and 2 females, aged $18-55$ years) investigated the interaction between raltegravir and maraviroc. The following dosing sequence was administered: raltegravir $400 \mathrm{mg}$ twice daily was given for 3 days, followed by a 2-day washout period, followed by maraviroc $300 \mathrm{mg}$ twice daily given for 6 days, followed by 3 days of maraviroc combined with raltegravir in the doses listed above. When combined, the exposures of both drugs decreased. The maraviroc $\mathrm{AUC}_{12}, \mathrm{C}_{\max }$ and $\mathrm{C}_{\min }$ GMRs were 0.86 (90\% CI 0.80, 0.92), 0.79 (90\% CI 0.67, 0.94) and 0.90 (90\% CI 0.85, 0.96 ), respectively. The raltegravir $\mathrm{AUC}_{12}, \mathrm{C}_{\max }$ and $\mathrm{C}_{\min }$ GMRs were 0.63 (90\% CI 0.44, $0.90), 0.67$ (90\% CI 0.41, 1.08) and 0.72 (90\% CI 0.58, 0.91), respectively. Since the reduction in maraviroc exposure was not considered to be clinically significant, no dosage adjustment was recommended. The marked reduction in raltegravir exposure may be a cause for concern, but no recommendations have yet been made in the US Department of Health and Human Services (DHHS) treatment guidelines or the raltegravir prescribing information. Given the large inter- and intrasubject variability in the pharmacokinetics of raltegravir (three of the subjects had increased, rather than decreased, raltegravir exposure) more studies are needed to understand this interaction.[101,108]

Maraviroc and Anti-Infectives: In 12 healthy male subjects, ketoconazole $400 \mathrm{mg}$ once daily in combination with maraviroc $100 \mathrm{mg}$ twice daily produced a significant increase in the maraviroc $\mathrm{AUC}_{12}$ and $\mathrm{C}_{\max }$ GMRs: $5.01(90 \% \mathrm{CI} 3.98,6.29)$ and 3.38 (90\% CI 2.38, 4.78), respectively. Because of the profound drug-drug interactions, these two compounds should not be used together.[99]

The potent CYP3A enzyme-inducing capacity of rifampicin produces profound declines in maraviroc exposure. In 12 healthy subjects given the combination of rifampicin $600 \mathrm{mg}$ once daily and maraviroc $100 \mathrm{mg}$ twice daily, the maraviroc $\mathrm{AUC}_{12}$ and $\mathrm{C}_{\max }$ declined by $67 \%$ and $70 \%$, respectively. Doubling the maraviroc dose to $200 \mathrm{mg}$ twice daily overcame the reduction in the $\mathrm{AUC}_{12}$ and $\mathrm{C}_{\max }$ seen with maraviroc $100 \mathrm{mg}$ plus rifampicin $600 \mathrm{mg}$ once daily (the GMRs for the $\mathrm{AUC}_{12}$ and $\mathrm{C}_{\max }$ increased to 0.99 and 0.97 , respectively). [105] The combination of maraviroc, rifampicin and protease inhibitors was not studied. However, it is recommended that this combination use the unadjusted dose of maraviroc. $[90,101]$

No data have been generated for the combination of maraviroc and rifabutin. The induction potential of rifabutin may decrease maraviroc exposures; however, rifabutin is considered not to have a clinically significant effect on the pharmacokinetics of CYP substrates. The DHHS treatment guidelines (November 2008) state that dosage adjustment is not warranted in concomitant administration of maraviroc and rifabutin, but close monitoring of viral response may be needed.[109] 
The effect of maraviroc on the pharmacokinetics of midazolam was studied in 12 healthy subjects using a double-blind, placebo-controlled, crossover study design. Maraviroc was administered at $300 \mathrm{mg}$ twice daily for 7 days and midazolam was given as a single dose of $7.5 \mathrm{mg}$ on day 7. The GMRs for the midazolam $\mathrm{AUC}_{12}$ and $\mathrm{C}_{\max }$ (maraviroc vs placebo) were 1.18 (90\% CI 1.04, 1.34) and 1.21 (90\% CI 0.92, 1.60), respectively, showing that maraviroc has a minor effect on midazolam pharmacokinetics, which is likely to be the case for other substrates of CYP3A4. No dosage adjustment is required for concomitant administration of maraviroc and midazolam.[87]

In 14 healthy female subjects, the effect of maraviroc on the pharmacokinetics of ethinylestradiol and levonorgestrel was studied in a double-blind, placebo-controlled, crossover study. Maraviroc was administered at $300 \mathrm{mg}$ twice daily for 10 days with a single dose on day 11 , and ethinylestradiol $30 \mu \mathrm{g}$ and levonorgestrel $150 \mu \mathrm{g}$ were given once daily on days 2-8. Comparing maraviroc plus ethinylestradiol/levonorgestrel with placebo plus ethinylestradiol/levonorgestrel, the $\mathrm{AUC}_{24}$ and $\mathrm{C}_{\max }$ GMRs for ethinylestradiol were 0.996 (90\% CI 0.945, 1.06) and 0.984 (90\% CI 0.913, 1.06), respectively, and the $\mathrm{AUC}_{24}$ and $\mathrm{C}_{\max }$ GMRs for levonorgestrel were 0.977 (90\% CI 0.92, 1.04) and 1.00 (90\% CI 0.93, 1.08 ), respectively. No dosage adjustment is necessary when combining maraviroc with these oral contraceptives.[87]

\subsection{Vicriviroc}

Vicriviroc is a reversible noncompetitive CCR5 chemokine receptor inhibitor that is currently in phase III studies (figure 1e).

3.2.1 Pharmacology-The molecular weight of vicriviroc is $533.63 \mathrm{~g} / \mathrm{mol}$. In human plasma, approximately $84 \%$ is bound to proteins.[110] The in vitro binding affinity $\left(\mathrm{K}_{\mathrm{i}}\right)$ of vicriviroc for CCR5 receptors is $0.8 \mathrm{nmol} / \mathrm{L}$. The geometric mean $\mathrm{EC}_{50}$ values for various HIV-1 CCR5-tropic isolates range from 0.04 to $2.3 \mathrm{nmol} / \mathrm{L}$, and $\mathrm{EC}_{90}$ values range from 0.45 to $18 \mathrm{nmol} / \mathrm{L}$. Zidovudine, lamivudine, efavirenz, indinavir and enfuvirtide are reported to have synergistic effects on HIV-1 replication with vicriviroc using a CCR5-tropic clinical isolate in vitro.[110]

Using recombinant CYP enzymes, vicriviroc metabolites are formed by CYP3A4, CYP3A5 and CYP2C9. CYP3A4 is a major contributor to metabolite formation, and CYP3A5 and CYP2C9 are minor contributors. This is confirmed by human liver microsomal incubations. When combined with the potent CYP3A4 inhibitor ketoconazole, vicriviroc metabolism is $90 \%$ inhibited. Furthermore, incubation with an anti-CYP3A4/5 specific antibody inhibits $>80 \%$ of vicriviroc metabolism.[111]

Vicriviroc is not a significant substrate of P-glycoprotein. The efflux ratio obtained from Caco-2 permeability studies is approximately 0.6 , meaning that more vicriviroc is absorbed than effluxed from the enterocyte.[112]

3.2.2 Pharmacokinetics-In HIV-infected individuals, the pharmacokinetic profile of vicriviroc has been studied at doses of 10, 25 and $50 \mathrm{mg}$ twice daily. Steady-state conditions are reached in approximately 12 days, with a linear dose-pharmacokinetic relationship. The reported median steady-state pharmacokinetic parameters using $50 \mathrm{mg}$ twice daily include an $\mathrm{AUC}_{12}$ of $2290 \mathrm{ng} \cdot \mathrm{h} / \mathrm{mL}, \mathrm{C}_{\max }$ of $342 \mathrm{ng} / \mathrm{mL}, \mathrm{C}_{\min }$ of $117 \mathrm{ng} / \mathrm{mL}, \mathrm{t}_{\max }$ of 1.5 hours, elimination half-life of 28 hours, apparent oral clearance of $21 \mathrm{~L} / \mathrm{h}$ and volume of distribution of 778 L.[113]

A slight food effect is evident with vicriviroc absorption. A comparison of a high-fat meal and fasting conditions in 20 healthy subjects given a single dose of vicriviroc $50 \mathrm{mg}$ found a 
$\mathrm{C}_{\max }$ decrease of $58 \%$ (range 52-65\%), although the relative oral bioavailability was $107 \%$ (range 101-113\%). Because exposure is minimally affected, as shown by the relative oral bioavailability, vicriviroc can be administered without regard to food.[114]

3.2.3 Drug-Drug Interactions-Vicriviroc interactions have been evaluated with selected NRTIs, efavirenz and multiple protease inhibitors. For the following drug interactions, no data have been reported on the effect of vicriviroc on the concomitant regimen.

Vicriviroc and Protease Inhibitors: In a study of 46 healthy subjects, the pharmacokinetic profile of vicriviroc $10 \mathrm{mg}$ given twice daily was evaluated in combination with ritonavir $100 \mathrm{mg}$ once daily, $100 \mathrm{mg}$ twice daily, $200 \mathrm{mg}$ twice daily or $400 \mathrm{mg}$ twice daily. Ritonavir increased the vicriviroc $\mathrm{AUC}_{12}$ and $\mathrm{C}_{\max }$ by $469-585 \%$ and $301-395 \%$, respectively.[115] This demonstrated that regardless of the ritonavir dose, vicriviroc exposure was increased to a similar extent. Dosage adjustment will not be necessary, because vicriviroc will require boosting by ritonavir ( $30 \mathrm{mg} / 100 \mathrm{mg}$ once daily).

The pharmacokinetics of vicriviroc $15 \mathrm{mg}$ once daily in combination with ritonavir $100 \mathrm{mg}$ once or twice daily in 40 healthy subjects were compared with those of vicriviroc combined with the following ritonavir-enhanced regimens: atazanavir/ritonavir $300 \mathrm{mg} / 100 \mathrm{mg}$ once daily ( $\mathrm{n}=8$ ), indinavir/ritonavir $800 \mathrm{mg} / 100 \mathrm{mg}$ twice daily $(\mathrm{n}=8)$, fosamprenavir/ritonavir $700 \mathrm{mg} / 100 \mathrm{mg}$ twice daily $(\mathrm{n}=8)$, nelfinavir/ritonavir $1250 \mathrm{mg} / 100 \mathrm{mg}$ twice daily $(\mathrm{n}=8$; 3 dropped out) and saquinavir/ritonavir $1000 \mathrm{mg} / 100 \mathrm{mg}$ twice daily $(\mathrm{n}=8)$. No clinically significant changes were noted in vicriviroc exposure with any of the protease inhibitor combinations. The GMRs for the $\mathrm{AUC}_{12}$ and $\mathrm{C}_{\max }$ of vicriviroc with atazanavir were 1.11 (90\% CI 1.08, 1.15) and 1.1 (90\% CI 1.0, 1.21), respectively; with indinavir were 1.03 (90\% CI $0.89,1.19)$ and $0.93(90 \%$ CI $0.82,1.05)$, respectively; with fosamprenavir were 0.98 $(90 \%$ CI $0.81,1.18)$ and $1.0(90 \%$ CI $0.81,1.24)$, respectively; with nelfinavir were 0.96 $(90 \%$ CI $0.86,1.08)$ and 0.88 (90\% CI 0.76, 1.03), respectively; and with saquinavir were 1.11 (90\% CI 0.99, 1.24) and 1.18 (90\% CI 1.08, 1.29), respectively.[116] Therefore, no dosage adjustment is needed when vicriviroc is combined with these boosted protease inhibitor regimens. Similarly, a study in 24 healthy subjects found the exposure of vicriviroc combined with ritonavir to be similar to that of vicriviroc combined with lopinavir/ritonavir, suggesting no vicriviroc dosage adjustment will be needed should these drugs be combined during therapy.[117]

A study of the interaction between vicriviroc $15 \mathrm{mg}$ and tipranavir/ritonavir $500 \mathrm{mg} / 200 \mathrm{mg}$ twice daily was evaluated in eight healthy subjects, and vicriviroc exposures were compared with a dosage regimen of vicriviroc/ritonavir $15 \mathrm{mg} / 100 \mathrm{mg}$ twice daily. No difference in vicriviroc exposure was found.[118]

Vicriviroc and Reverse Transcriptase Inhibitors: No significant interactions occur between vicriviroc (50 $\mathrm{mg}$ twice daily) and lamivudine ( $150 \mathrm{mg}$ twice daily) or zidovudine (300 mg twice daily). In 36 healthy subjects, the GMRs for the $\mathrm{AUC}_{12}$ and $\mathrm{C}_{\max }$ of vicriviroc in combination with zidovudine/lamivudine compared with vicriviroc alone were $0.91(90 \% 0.77,1.09)$ and $0.92(90 \% 0.77,1.10)$, respectively. Similarly, the $\mathrm{AUC}_{12}$ and $\mathrm{C}_{\max }$ GMRs for zidovudine were $0.93(90 \% 0.76,1.14)$ and $0.92(90 \% 0.68,1.25)$, respectively, and the $\mathrm{AUC}_{12}$ and $\mathrm{C}_{\max }$ GMRs for lamivudine were $0.96(90 \% 0.81,1.13)$ and $0.85(90 \% 0.69,1.05)$, respectively.[119] Additionally, no significant interaction was seen in 24 healthy subjects when vicriviroc $10 \mathrm{mg}$ twice daily was combined with tenofovir $300 \mathrm{mg}$ once daily.[120] 
Efavirenz significantly induces the metabolism of vicriviroc. In 36 healthy subjects, efavirenz $600 \mathrm{mg}$ once daily for 14 days decreased the $\mathrm{AUC}_{24}$ and $\mathrm{C}_{\max }$ of vicriviroc $10 \mathrm{mg}$ once daily by a mean of $81 \%(90 \%$ CI 74,86$)$ and $67 \%(90 \%$ CI 56,75$)$, respectively. When ritonavir $100 \mathrm{mg}$ was added to the vicriviroc regimen once daily, the inductive effects were attenuated. The vicriviroc $\mathrm{AUC}_{24}$ and $\mathrm{C}_{\max }$ increased by $384 \%$ (90\% CI 279,529$)$ and $196 \%$ (90\% CI 147, 261), respectively. Therefore, vicriviroc and efavirenz may be administered together, provided that ritonavir is also utilized in the regimen.[121]

\subsection{INCB 9471}

INCB 9471 is a reversible noncompetitive CCR5 antagonist which has recently completed phase IIa studies. This compound binds to CCR5 receptors slightly differently from other CCR5 receptor antagonists, and its favourable pharmacokinetic profile allows once-daily administration and no requirement for boosting (figure 1f).[122]

3.3.1 Pharmacology-The molecular weight of INCB 9471 is $559.67 \mathrm{~g} / \mathrm{mol}$. In vitro, the mean $\mathrm{IC}_{90}$ of INCB 9471 for preventing infection ofPBMCs was $9.3 \mathrm{nmol} / \mathrm{L}$. In assays using the native ligand for chemokine receptors, INCB 9471 was shown to have high receptor selectivity for CCR5, with an $\mathrm{IC}_{50}$ of $7.1 \mathrm{nmol} / \mathrm{L}$. INCB 9471 is $84 \%$ bound to plasma proteins.[123] The protein-binding corrected $\mathrm{IC}_{90}$ is $50-60 \mathrm{nmol} / \mathrm{L} .[124]$

INCB 9471 is a weak inhibitor of CYP1A2, CYP2C9, CYP2C19, CYP2D6 and CYP3A4 activity $\left(\mathrm{IC}_{50}\right.$ values all $>25 \mu \mathrm{mol} / \mathrm{L}$ ). It was also reported that based on reporter gene assay results, the drug is unlikely to induce CYP3A4.[124]

3.3.2 Pharmacokinetics-In a single dose-ranging study in 12 healthy subjects receiving INCB $94712.5 \mathrm{mg}$ to $300 \mathrm{mg}$, the $\mathrm{C}_{\max }$ ranged from 8.9 to $1300 \mathrm{nmol} / \mathrm{L}$, the $\mathrm{t}_{\max }$ from 1.9 to 1.4 hours, the elimination half-life from 3.4 to 48.0 hours and the $\mathrm{AUC}_{\infty}$ from 59 to 21 $163 \mathrm{nmol} \bullet \mathrm{h} / \mathrm{L}$.[124] In a repeat-dose study in 12 healthy subjects, the pharmacokinetics of INCB $947150 \mathrm{mg}$ twice daily, $100 \mathrm{mg}$ twice daily, $150 \mathrm{mg}$ once daily and $200 \mathrm{mg}$ once daily were assessed and exhibited a dose-linear relationship. The $\mathrm{C}_{\max }$ ranged from 437 to $1363 \mathrm{nmol} / \mathrm{L}$, the $t_{\max }$ from 2.1 to 2.7 hours, the $\mathrm{C}_{\min }$ from 231 to $416 \mathrm{nmol} / \mathrm{L}$ and the AUC during the dosage interval $\left(\mathrm{AUC}_{\tau}\right)$ from 3843 to $16802 \mathrm{nmol} \bullet \mathrm{h} / \mathrm{L}$. The elimination half-life was approximately 42 to 56 hours. The $\mathrm{C}_{\min }$ for the $200 \mathrm{mg}$ dose $(416 \mathrm{nmol} / \mathrm{L})$ was 8 -fold higher than the protein binding-adjusted $\mathrm{IC}_{90}$ in PBMCs.[124] Therefore, the $200 \mathrm{mg}$ oncedaily dose is being studied in phase IIb investigations.

3.3.3 Drug-Drug Interactions-Minimal information is available on the pharmacokinetic drug-drug interaction potential of INCB 9471. In one study in 12 healthy subjects, INCB $947125 \mathrm{mg}$ twice daily was combined with ritonavir $100 \mathrm{mg}$ twice daily. Compared with INCB 9471 alone, ritonavir increased the $\mathrm{AUC}_{12}$ and $\mathrm{C}_{\max }$ by $1300 \%$ and $55 \%$, respectively.[125] Therefore, INCB 9471 will most likely require dose adjustment when combined with boosted protease inhibitor regimens.

\section{Integrase Inhibitors}

\subsection{Raltegravir}

Raltegravir, also known as MK 0518, is an integrase strand transfer inhibitor from the hydroxypyrimidine carboxamide class.[126] It is active against multidrug-resistant CCR5tropic and CXCR4-tropic HIV-1, and the drug has activity against HIV-2.[127] Raltegravir blocks the ability of integrase to catalyse the stepwise process by which HIV-1 DNA is inserted into host cell DNA (figure 1g). 
4.1.1 Pharmacology-The molecular weight of raltegravir is $482.507 \mathrm{~g} / \mathrm{mol}$. In $50 \%$ human serum, the raltegravir $\mathrm{IC}_{95}$ (mean $\pm \mathrm{SD}$ ) is $31 \pm 20 \mathrm{nmol} / \mathrm{L}$. Raltegravir is approximately $83 \%$ bound to human plasma proteins.[126]

Raltegravir is primarily metabolized in the liver through uridine diphosphate glucuronosyltransferase (UGT) 1A1-mediated glucuronidation. A study investigating the excretion of a $200 \mathrm{mg}$ dose of raltegravir in eight healthy subjects estimated the fraction of raltegravir metabolized by UGT1A1 to be 0.7.[128] Raltegravir is neither a potent inhibitor nor an inducer of CYP enzymes or drug transporters and thus has reduced potential for antiretroviral drug interactions. Based on these properties, raltegravir is not expected to alter the pharmacokinetics of drugs that are substrates of CYP3A4, UGT1A1, UGT2B7 or Pglycoprotein. Since raltegravir is not metabolized by CYP3A or transported by Pglycoprotein, pharmacokinetic enhancement with low-dose ritonavir is not required to achieve therapeutic concentrations.[126]

4.1.2 Pharmacokinetics-In a study of 24 healthy male subjects, raltegravir was rapidly absorbed ( $\mathrm{t}_{\max } \sim 3$ hours). The volume of distribution of raltegravir is approximately $6-7 \mathrm{~L} /$ $\mathrm{kg}$, the apparent oral clearance is $0.5 \mathrm{~L} / \mathrm{h} / \mathrm{kg}$ and the terminal elimination half-life is $\sim 9$ hours.[129] Bioavailability is estimated at 30\%. A dose-ranging study in 35 antiretroviralnaïve HIV-1-infected subjects given doses of raltegravir 100, 200, 400 and $600 \mathrm{mg}$ twice daily demonstrated that the geometric mean $\mathrm{C}_{12}$ in each dosage group exceeded the estimated $\mathrm{IC}_{95}$ of $33 \mathrm{nmol} / \mathrm{L} .[130] \mathrm{A}$ high-fat meal slows the rate of raltegravir absorption, increasing the $\mathrm{C}_{12}$ by $750 \%$, the $\mathrm{AUC}_{12}$ by $19 \%$ and the $\mathrm{t}_{\max }$ by 7.3 hours and decreasing the $\mathrm{C}_{\max }$ by $34 \%$.[131]

Raltegravir is generally well tolerated in patients with moderate hepatic impairment or severe renal insufficiency. These conditions have no clinically important effects upon the pharmacokinetics of raltegravir, and no dose adjustment is required.[132]

4.1.3 Drug-Drug Interactions-Pharmacokinetic drug-drug interaction studies have demonstrated clinically insignificant changes in raltegravir exposure when coadministered with efavirenz, ritonavir, tenofovir[126] and tipranavir.[133]

Raltegravir and Protease Inhibitors: No adjustment in the dosage of raltegravir is required for coadministration with ritonavir, atazanavir or tipranavir. In the presence of ritonavir, the GMRs for the raltegravir $\mathrm{AUC}_{12}, \mathrm{C}_{\max }$ and $\mathrm{C}_{12}$ are 0.84, 0.99 and 0.76, respectively. These results are not considered clinically significant.[134]

A study of the effects of atazanavir on the pharmacokinetics of raltegravir was conducted in 12 healthy subjects; the $C_{12}$ values of raltegravir increased by $95 \%$ in the presence of atazanavir compared with raltegravir administered alone.[131] Despite this pharmacological change, the combination of atazanavir and raltegravir was not associated with any adverse events, and no dose adjustment appears necessary.[126] In a study of 15 healthy subjects, the combination of tipranavir and ritonavir decreased the $\mathrm{C}_{12}$ values of raltegravir by $55 \%$. [135] However, the $C_{12}$ values were shown to span a 5-log range in the phase III BENCHMRK studies.[136] As a result, the decrease associated with tipranavir/ritonavir coadministration is not considered to be of clinical concern. Moreover, approximately 100 subjects received raltegravir in combination with tipranavir/ritonavir in the BENCHMRK studies. Comparable efficacy was observed in this subgroup relative to those not receiving tipranavir/ritonavir.[137] Taken together, these data indicate that tipranavir/ritonavir may be coadministered with raltegravir without dose adjustment of raltegravir. Since raltegravir concentrations may be decreased when administered in conjunction with tipranavir/ritonavir, the therapeutic efficacy of raltegravir should be monitored closely. 
Raltegravir and Reverse Transcriptase Inhibitors: Since raltegravir is primarily metabolized by glucuronidation and displays no inductive or inhibitory action on CYP enzymes in vitro, raltegravir is not expected to affect the pharmacokinetic activity of NNRTIs.

The interactions between raltegravir $400 \mathrm{mg}$ twice daily and tenofovir $300 \mathrm{mg}$ once daily were examined in a three-period, open-label study in ten healthy subjects. When coadministered with tenofovir, the GMRs for the $\mathrm{AUC}_{12}, \mathrm{C}_{\max }$ and $\mathrm{C}_{12}$ of raltegravir were 1.49 (90\% CI 1.15, 1.94), 1.64 (90\% CI 1.16, 2.32) and 1.03 (90\% CI 0.73, 1.45), respectively. For tenofovir, the GMRs for the $\mathrm{AUC}_{24}, \mathrm{C}_{\max }$ and $\mathrm{C}_{24}$ were $0.90(90 \% \mathrm{CI}$ $0.82,0.99), 0.77$ (90\% CI 0.69, 0.85) and 0.87 (90\% CI 0.74, 1.02), respectively. Since tenofovir is primarily eliminated through both glomerular filtration and active tubular secretion, these results indicate an expected lack of interaction between tenofovir and raltegravir.[138]

The interaction between raltegravir/ritonavir and efavirenz was examined in 12 healthy subjects. Coadministration of efavirenz $600 \mathrm{mg}$ once daily with single doses of raltegravir $400 \mathrm{mg}$ decreased the AUC and $\mathrm{C}_{\max }$ of raltegravir by $36 \%$ and the $\mathrm{C}_{\min }$ by $21 \%$. The observed reduction in raltegravir pharmacokinetics was not considered clinically meaningful. Ritonavir dosing has marginal effects on raltegravir pharmacokinetics, as determined by the $\mathrm{C}_{12}, \mathrm{AUC} 1_{\infty}$ and $\mathrm{C}_{\max }$ GMRs of 0.99 (90\% CI 0.70, 1.40), 0.84 (90\% CI $0.70,1.01)$ and $0.76(90 \% \mathrm{CI} 0.55,1.04)$, respectively.[134,139] A summary of the interactions between raltegravir and etravirine is provided in section 2.1.3.

Raltegravir and Sedatives: The interaction between a single, $2.0 \mathrm{mg}$ dose of midazolam hydrochloride syrup $(2 \mathrm{mg} / \mathrm{mL})$ and raltegravir $400 \mathrm{mg}$ twice daily was evaluated in ten healthy subjects ( 7 male, 3 female) who participated in a two-period, open-label, fixedsequence dosing study. The GMRs comparing the pharmacokinetic parameters of midazolam/raltegravir and midazolam alone were $0.92(90 \%$ CI $0.82,1.03)$ for the $\mathrm{AUC}_{\infty}$ and $1.03(90 \% \mathrm{CI} 0.87,1.22)$ for the $\mathrm{C}_{\max }$. This result provides additional evidence to indicate that raltegravir is neither an inducer nor an inhibitor of CYP enzyme activity.[140]

Raltegravir and Antibacterials: The pharmacokinetic interaction between rifampicin 600 $\mathrm{mg}$ daily and a single $400 \mathrm{mg}$ dose of raltegravir was evaluated in a two-period, open-label, fixed-sequence dosing study of ten healthy subjects ( 7 male, 3 female). Raltegravir exposure was decreased by $40 \%$ when combined with rifampicin, and caution should be used when these drugs are combined.[141]

Raltegravir and Oral Contraceptives: Combining raltegravir $400 \mathrm{mg}$ twice daily with an oral contraceptive containing ethinylestradiol and norgestimate does not alter the overall exposure to the oral contraceptive.[142]

\subsection{Elvitegravir}

Elvitegravir is currently in phase III clinical trials (figure $1 \mathrm{~h}$ ).

4.2.1 Pharmacology-The molecular weight of elvitegravir is $447.884 \mathrm{~g} / \mathrm{mol}$.[143] Elvitegravir demonstrates potent, selective inhibition of viral DNA integration into host chromosomal DNA at an adjusted $\mathrm{IC}_{50}$ of $16 \mathrm{nmol} / \mathrm{L}$.[144] Elvitegravir is primarily metabolized by CYP3A. It undergoes secondary metabolic processing by glucuronidation through UGT1A1 and UGT1A3. The metabolic activity of UGT1A1 produces the metabolite M1, while that of UGT1A3 produces the metabolite M4. Both metabolites are less potent than the parent drug. M1 is 5- to 18-fold less potent and M4 is 10- to 38-fold less 
potent in antiviral activity assays, and both metabolites are not present in plasma in substantial concentrations. Thus, M1 and M4 do not appear to contribute to the antiviral activity of elvitegravir.[144]

4.2.2 Pharmacokinetics-Pharmacokinetic data generated in studies with both treatment-naïve and treatment-experienced populations demonstrated an approximate 20fold enhancement in elvitegravir exposure when administered in combination with low-dose ritonavir. HIV-infected patients taking $800 \mathrm{mg}$ once daily exhibited a mean (CV) $\mathrm{AUC}_{24}$ of $5510 \mathrm{ng} \cdot \mathrm{h} / \mathrm{mL}(54 \%), \mathrm{C}_{\max }$ of $940 \mathrm{ng} / \mathrm{mL}(54 \%), \mathrm{C}_{\min }$ of $13.6(69 \%)$ and elimination halflife of 3.8 hours at steady state. Pharmacokinetic parameters in HIV-infected patients given elvitegravir $50 \mathrm{mg}$ once daily combined with ritonavir $100 \mathrm{mg}$ included an $\mathrm{AUC}_{24}$ of 8840 $\mathrm{ng} \bullet \mathrm{h} / \mathrm{mL}(26 \%), \mathrm{C}_{\max }$ of $745 \mathrm{ng} / \mathrm{mL}(20 \%), \mathrm{C}_{\min }$ of $135 \mathrm{ng} / \mathrm{mL}(37 \%)$ and mean elimination half-life of 8.6 hours.[145] Ritonavir-boosted dosing conditions serve to enhance the oral bioavailability of elvitegravir while reducing its systemic clearance, resulting in overall net inhibition of elvitegravir metabolism.

A study in 32 Japanese healthy male subjects determined that the absorption of elvitegravir is approximately 3 -fold higher in the presence of food. Based on this finding, it is recommended that elvitegravir be taken with food.[146]

4.2.3 Drug-Drug Interactions-Drug-drug interaction studies evaluating the pharmacokinetics of NRTIs and NNRTIs have been completed. These studies demonstrated that elvitegravir/ritonavir can be coad-ministered with zidovudine, didanosine, stavudine, abacavir and tipranavir without the need for dose adjustment. Coad-ministration of elvitegravir/ritonavir with NNRTIs also does not result in drug-drug interactions. No additional drug interaction information for elvitegravir is available at this time.

Elvitegravir and Protease Inhibitors: In a study in healthy subjects, coadministration of elvitegravir with tipranavir/ritonavir was not found to produce any significant change in the steady-state pharmacokinetics of either drug. Subjects in this crossover study received one of the following for 14 days: elvitegravir/ritonavir $200 \mathrm{mg} / 100 \mathrm{mg}$ once daily, tipranavir/ ritonavir $500 \mathrm{mg} / 200 \mathrm{mg}$ twice daily or elvitegravir $200 \mathrm{mg}$ once daily plus tipranavir/ ritonavir $500 \mathrm{mg} / 200 \mathrm{mg}$ twice daily. The percent GMRs for the $\mathrm{AUC}_{\tau}, \mathrm{C}_{\max }$ and $\mathrm{C}_{\text {trough }}$ during the dosage interval $\left(\mathrm{C}_{\tau}\right)$ of elvitegravir administered with tipranavir/ritonavir compared with elvitegravir/ritonavir alone were 92.4 (90\% CI 78.7, 108), 106 (90\% CI 89.4, 126) and 90.4 (90\% CI 69.8, 117), respectively. The GMRs for the $\mathrm{AUC}_{\tau}, \mathrm{C}_{\max }$ and $\mathrm{C}_{\tau}$ of tipranavir/ritonavir administered with elvitegravir compared with tipranavir/ritonavir alone were 88.9 (90\% CI 80.0, 98.8), 91.6 (90\% CI 83.8, 100) and 88.9 (90\% CI 77.4, 102), respectively. No dose adjustment is necessary when coadministering elvitegravir and tipranavir/ritonavir.[147]

Similarly, a study in 20 healthy subjects showed no significant interaction between elvitegravir and darunavir/ritonavir. Participants received either elvitegravir/ritonavir 125 $\mathrm{mg} / 100 \mathrm{mg}$ once daily, darunavir/ritonavir $600 \mathrm{mg} / 100 \mathrm{mg}$ twice daily or elvitegravir 125 $\mathrm{mg}$ once daily plus darunavir/ritonavir $600 \mathrm{mg} / 100 \mathrm{mg}$ twice daily. The GMRs for the $\mathrm{AUC}_{\tau}, \mathrm{C}_{\max }$ and $\mathrm{C}_{\tau}$ of elvitegravir administered with darunavir/ritonavir compared with elvitegravir/ritonavir alone were 111 (90\% CI 99.1, 122), 113 (90\% CI 103, 124) and 118 (90\% CI 106, 131), respectively. The GMRs for the $\mathrm{AUC}_{\tau}, \mathrm{C}_{\max }$ and $\mathrm{C}_{\tau}$ of darunavir/ ritonavir administered with elvitegravir compared with darunavir/ritonavir alone were 88.7 (90\% CI 82.3, 95.6), 89.4 (90\% CI 85.0, 94.1) and 82.8 (90\% CI 73.7, 92.9), respectively. No dose adjustment is necessary when coadministering elvitegravir and darunavir/ritonavir. $[147,148]$ 
Elvitegravir and Reverse Transcriptase Inhibitors: A study of 31 healthy subjects found that the mean exposures of a single tablet of didanosine $400 \mathrm{mg}$ were approximately $15 \%$ lower upon coadministration with elvitegravir/ritonavir $200 \mathrm{mg} / 100 \mathrm{mg}$. The GMRs for the didanosine $\mathrm{C}_{\max }$ and AUC administered with elvitegravir/ritonavir compared with didanosine administered alone were 0.84 (90\% CI 0.67, 1.05) and 0.86 (90\% CI 0.75, 0.99), respectively.[144] Similar results were seen with stavudine $40 \mathrm{mg}$. The GMRs for the stavudine $\mathrm{C}_{\max }$ and AUC when coadministered with elvitegravir/ritonavir were 0.99 (90\% CI $0.93,1.06)$ and 1.07 (90\% CI 1.05, 1.08), respectively.[144]

Abacavir undergoes partial hepatic biotransformation via glucuronyltransferase.[149] Since elvitegravir undergoes secondary metabolism by glucuronyltransferase, the interaction between elvitegravir/ritonavir $200 \mathrm{mg} / 100 \mathrm{mg}$ and abacavir was examined in 26 healthy subjects. All subjects received a single $600 \mathrm{mg}$ dose of abacavir on treatment day 1 , elvitegravir/ritonavir $200 \mathrm{mg} / 100 \mathrm{mg}$ once daily on treatment days 5-14, and elvitegravir/ ritonavir $200 \mathrm{mg} / 100 \mathrm{mg}$ plus abacavir $600 \mathrm{mg}$ on treatment day 15 . Abacavir pharmacokinetics were not affected when combined with elvitegravir. The GMRs for the abacavir $\mathrm{C}_{\max }$ and AUC when administered with elvitegravir/ritonavir were 0.88 (90\% CI $0.82,0.94)$ and 0.84 (90\% CI 0.81, 0.86), respectively.[144] Coadministration with abacavir had no significant impact on the pharmacokinetic parameters of elvitegravir.

Zidovudine undergoes partial hepatic biotransformation via glucuronyltransferase.[150] The pharmacokinetic interaction between elvitegravir/ritonavir and zidovudine and its glucuronide was studied in 28 healthy subjects. Elvitegravir/ritonavir was administered at $200 \mathrm{mg} / 100 \mathrm{mg}$ once daily and zidovudine at $300 \mathrm{mg}$ twice daily. Pharmacokinetic parameters were observed with a two-way crossover study design for up to 27 days. Upon coadministration with elvitegravir/ritonavir, the pharmacokinetic parameters of elvitegravir, zidovudine and the glucuronide of zidovudine were not altered. The GMRs for the zidovudine $\mathrm{C}_{\max }$ and AUC were 0.88 (90\% CI 0.77, 1.01) and 0.86 (90\% CI 0.80, 0.93), respectively, and the GMRs for the zidovudine glucuronide $\mathrm{C}_{\max }$ and AUC were 1.11 (90\% CI 1.01, 1.21) and 1.05 (90\% CI 1.01, 1.08), respectively.[144]

Coadministration of elvitegravir/ritonavir with the fixed-dose combination formula of emtricitabine/tenofovir disoproxil fumarate did not yield any clinically significant drug-drug interactions between all compounds in 26 healthy subjects.[151]

An evaluation of the pharmacokinetic interaction between elvitegravir/ritonavir and lamivudine has not been completed; however, given the lack of a pharmacokinetic interaction with coadministration of elvitegravir/ritonavir and emtricitabine, a pharmacokinetic interaction with coadministration of elvitegravir/ritonavir and lamivudine is unlikely.[151]

No clinically relevant drug-drug interactions between elvitegravir/ritonavir and etravirine (TMC125) have been found. The results of a study of 34 healthy subjects (17 male, 17 female) demonstrated that coadministration of elvitegravir/ritonavir $150 \mathrm{mg} / 100 \mathrm{mg}$ once daily and etravirine (F060) $200 \mathrm{mg}$ twice daily is well tolerated and that no dose adjustment is required for coadministration of these two drugs. The GMRs for the $\mathrm{C}_{\max }, \mathrm{AUC}_{24}$ and $\mathrm{C}_{24}$ of elvitegravir (with ritonavir) administered with etravirine compared with elvitegravir administered alone with ritonavir were 1.07 (90\% CI 1.01, 1.13), 1.06 (90\% CI 1.0, 1.13) and 1.06 (90\% CI 0.97, 1.16), respectively.[44] The GMRs for etravirine alone were not reported.

Elvitegravir and Chemokine Receptor Antagonists: A study of the pharmacokinetic interaction between elvitegravir/ritonavir $150 \mathrm{mg} / 100 \mathrm{mg}$ twice daily and maraviroc $150 \mathrm{mg}$ 
twice daily in 36 healthy subjects demonstrated no effects on elvitegravir exposure, but maraviroc exposure increased by $115 \%\left(\mathrm{C}_{\max }\right)$ and $186 \%\left(\mathrm{AUC}_{12}\right)$. This increased exposure is within the range of increases observed when maraviroc is administered in combination with other CYP3A4 inhibitors. Since elvitegravir is metabolized by CYP3A4 and maraviroc is a CYP3A4 substrate, a reduced dose of maraviroc $(150 \mathrm{mg})$ should be administered when combined with elvitegravir/ritonavir.[107]

Elvitegravir and Acid-Reducing Agents: The pharmacokinetics of elvitegravir/ritonavir $50 \mathrm{mg} / 100 \mathrm{mg}$ alone or coadministered with an antacid or omeprazole $40 \mathrm{mg}$ were evaluated in a study of 12 seronegative subjects. Coad-ministration with the antacid or omeprazole occurred either simultaneously with elvitegravir/ritonavir or 2 or 4 hours apart from elvitegravir/ritonavir administration. Coadministration of elvitegravir/ritonavir with the antacid decreased the $\mathrm{C}_{\max }$, AUC and $\mathrm{C}_{\min }$ of elvitegravir by $47 \%, 45 \%$ and $41 \%$, respectively. A 2-hour dose separation between the two drugs decreased elvitegravir exposure by $10-20 \%$, and a 4 -hour dose separation resulted in a $<5 \%$ decrease in comparison with elvitegravir alone. Coadministration of elvitegravir and omeprazole did not affect the exposures of either drug. Therefore, elvitegravir/ritonavir may be coadministered with omeprazole but should be separated from an antacid by at least 2 hours.[152]

\section{Maturation Inhibitors}

\subsection{Bevirimat (PA 457)}

Bevirimat (PA 457) is the first compound in the novel class of antiretrovirals called maturation inhibitors, and it is currently in phase II development (figure 1i). Bevirimat inhibits HIV-1 gag processing, which blocks conversion of p25 to p24, a viral core protein. This results in defective viral core condensation and noninfectious viral particles. In essence, this compound is a protease inhibitor, but rather than directly inhibiting the enzyme, bevirimat attaches to the cleavage site of gag between the capsid protein and SP1. The capsid protein is a building block for a structure that surrounds and protects the viral RNA, which is required for maturation into an infectious virion, and SP1 is a transcriptional factor that HIV uses to activate proviral DNA transcription. Since this cleavage site is highly conserved, this mechanism may be favourable with respect to the development of resistance. [153] The $\mathrm{IC}_{50}$ for wild-type HIV-1 is approximately $10 \mathrm{nmol} / \mathrm{L}(5.8 \mathrm{ng} / \mathrm{mL})$.[153] The protein binding-adjusted $\mathrm{IC}_{90}$ is estimated to be $2.3 \mu \mathrm{g} / \mathrm{mL}$.[154]

5.1.1 Pharmacology-The molecular weight of bevirimat is $584.83 \mathrm{~g} / \mathrm{mol}$. The protein binding to human serum albumin is reported to be greater than $99.5 \%$, with no significant binding to $\alpha_{1}$-acid glycoprotein (Martin DE, Panacos Pharmaceuticals Inc., personal communication).

Bevirimat is a substrate of UGTs. The primary pathway of biotransformation is glucuronidation by UGT1A3.[155] Bevirimat also exhibits weak to moderate inhibition of the UGTs 1A1, 1A3, 1A4, 1A8, 1A10 and 2B7.[155]

In studies using human liver microsomes, the $\mathrm{IC}_{50}$ values of bevirimat for CYP1A2, CYP2C19, CYP2D6 and CYP3A4 were $>100 \mu \mathrm{mol} / \mathrm{L}$. The $\mathrm{IC}_{50}$ of CYP2C9 was $10 \mu \mathrm{mol} /$ L.[155] In a multiple-dose study in healthy subjects, the GMRs for urinary $6 \beta-$ hydroxycortisol/cortisol ratios (a crude measure of CYP3A induction) ranged from 1.02 $(90 \%$ CI $0.528,1.96)$ to 1.36 (90\% CI $0.693,2.67)$, suggesting no important inductive effects of bevirimat on CYP3A enzyme activity.[156] Bevirimat does not interact with Pglycoprotein.[157] 
5.1.2 Pharmacokinetics-In a study in 24 healthy male subjects given single doses of bevirimat 25 to $250 \mathrm{mg}$, the $\mathrm{t}_{\max }$ was achieved in approximately 2 hours, and the $\mathrm{AUC}_{\infty}$ and $\mathrm{C}_{\max }$ dose-exposure relationships were linear, ranging from approximately 170 to $2000 \mu \mathrm{g} \bullet$ $\mathrm{h} / \mathrm{mL}$ and from 3 to $30 \mu \mathrm{g} / \mathrm{mL}$, respectively.[154] In a multiple-dose study in 36 healthy subjects evaluating doses from 25 to $200 \mathrm{mg}$ once daily, an accumulation in bevirimat exposure was seen between day 1 and day 10 . The terminal elimination half-life for all doses ranged from 56 to 70 hours, and the steady-state oral clearance ranged from 173.9 to 185.2 $\mathrm{mL} / \mathrm{h}$.[156] Pharmacokinetic parameters were similar in a multiple-dose study in 32 HIVinfected patients: the mean (CV) elimination half-life was 62.7 hours (19\%) and the mean oral clearance was $210 \mathrm{~mL} / \mathrm{h}$.[158] In phase II studies, doses up to $400 \mathrm{mg}$ are being investigated.

\subsubsection{Drug-Drug Interactions}

Bevirimat and Protease Inhibitors: When coadministered with ritonavir, bevirimat exposure decreases. This is probably due to the UGT-inductive effects of ritonavir.

Beviramat $200 \mathrm{mg}$ once daily was coadministered with ritonavir 100 or $200 \mathrm{mg}$ twice daily. These combinations were well tolerated. The $\mathrm{AUC}_{24}$ and $\mathrm{C}_{\max }$ of beviramat decreased in a dose-dependent manner when combined with ritonavir. The GMRs for the $\mathrm{AUC}_{24}$ and $\mathrm{C}_{\max }$ of beviramat were 0.83 (90\% CI 0.75, 0.92) and 0.96 (90\% CI 0.87, 1.06), respectively, when combined with ritonavir $100 \mathrm{mg}$ twice daily. When combined with ritonavir $200 \mathrm{mg}$ twice daily, the GMRs for the $\mathrm{AUC}_{24}$ and $\mathrm{C}_{\max }$ of beviramat were 0.69 (90\% CI 0.62, 0.77) and 0.83 (90\% CI 0.75, 0.92), respectively. No notable changes were seen in ritonavir exposures.[159] The clinical significance of these changes in exposure are being further evaluated.

In a study of 48 healthy subjects, the combination of bevirimat and atazanavir was well tolerated, with no increase in bilirubin levels and no pharmacokinetic interactions being observed. Bevirimat $200 \mathrm{mg}$ once daily was combined with atazanavir $400 \mathrm{mg}$ once daily. Compared with the exposure of either drug alone, the GMRs for the $\mathrm{AUC}_{24}$ and $\mathrm{C}_{\max }$ were 0.92 (90\% CI 0.81, 1.09) and 0.96 (90\% CI 0.85,1.09), respectively, for bevirimat and 0.94 $(90 \%$ CI $0.78,1.13)$ and $0.94(90 \%$ CI $0.82,1.07)$, respectively, for atazanavir.[160] Therefore, no dose adjustment should be necessary when combining bevirimat and atazanavir.

\section{Conclusions}

Potent new antiretroviral drugs in existing and novel classes offer treatment-experienced HIV-infected patients the chance of durable, long-term suppression of HIV replication. However, the increase in antiretroviral drug options also increases the complexity of using novel combinations of these agents together. Most new agents have significant drug-drug interaction challenges, and the clinical significance of these interactions cannot always be determined in well controlled studies that take place in healthy subjects. A thorough knowledge of how these drugs are metabolized and eliminated from the body will assist in predicting and managing important and potentially detrimental drug-drug interactions.

\section{Acknowledgments}

This work was supported by Boehringer Ingelheim Pharmaceuticals, Inc. Dr Kashuba has received honoraria from Boehringer Ingelheim Pharmaceuticals, Inc. and Tibotec Pharmaceuticals, and grants from Merck, Pfizer, Tibotec, Abbott and Gilead. 


\section{References}

1. Prezista ${ }^{\circledR}$ (darunavir) tablet: US prescribing information. Raritan (NJ): Tibotec Therapeutics, 2008 Dec. [2009 Mar 25]. [online]. Available from URL: http://www.prezista.com/prezista/documents/us_package_insert.pdf

2. De Meyer S, Azijn H, Surleraux D, et al. TMC114, a novel human immunodeficiency virus type 1 protease inhibitor active against protease inhibitor-resistant viruses, including a broad range of clinical isolates. Antimicrob Agents Chemother 2005 Jun;49(6):2314-21. [PubMed: 15917527]

3. Dierynck I, De Wit M, Gustin E, et al. Binding kinetics of darunavir to human immunodeficiency virus type 1 protease explain the potent antiviral activity and high genetic barrier. J Virol 2007 Dec; 81(24):13845-51. [PubMed: 17928344]

4. Sekar, V.; Spinosa-Guzman, S.; Lefebvre, E., et al. Clinical pharmacology of TMC114 - a potent HIV protease inhibitor. XVI International AIDS Conference; 2006 Aug 13-18; Toronto (ON). abstract no. TUPE0083

5. Sekar, V.; De Meyer, S.; Vangeneugden, T., et al. Pharmacokinetic/pharmacodynamic analyses of TMC114 in the POWER 1 and POWER 2 trials in treatment-experienced HIV-infected patients. 13th Conference on Retroviruses and Opportunistic Infections; 2006 Feb 5-8; Denver (CO).

6. Profit L, Eagling VA, Back DJ. Modulation of P-glycoprotein function in human lymphocytes and Caco-2 cell monolayers by HIV-1 protease inhibitors. AIDS 1999 Sep 10;13(13):1623-7. [PubMed: 10509562]

7. Lee, LS.; Soon, GH.; Shen, P., et al. Efavirenz increases MRP1 efflux transporter function while darunavir inhibits MRP1 expression in healthy volunteers. 16th Conference on Retroviruses and Opportunistic Infections; 2009 Feb 8-11; Montreal (QC). abstract no. 705

8. Molina JM, Hill A. Darunavir (TMC114): a new HIV-1 protease inhibitor. Expert Opin Pharmacother 2007 Aug;8(12):1951-64. [PubMed: 17696796]

9. Rittweger M, Arastéh K. Clinical pharmacokinetics of darunavir. Clin Pharmacokinet 2007;46(9): 739-56. [PubMed: 17713972]

10. TMC114 investigator's brochure. 7. Co Cork, Ireland: Tibotec; 2006.

11. Sekar, V.; Guzman, S.; Stevens, T., et al. Absolute bioavailability of TMC114 administered in the absence and presence of low-dose ritonavir. 7th International Workshop on Clinical Pharmacology of HIV Therapy; 2006 Apr 20-22; Lisbon. abstract no. 86

12. Sekar V, Kestens D, Spinosa-Guzman S, et al. The effect of different meal types on the pharmacokinetics of darunavir (TMC114)/ritonavir in HIV-negative healthy volunteers. J Clin Pharmacol 2007 Apr;47(4):479-84. [PubMed: 17389557]

13. Busse KH, Penzak SR. Darunavir: a second-generation protease inhibitor. Am J Health Syst Pharm 2007 Aug 1;64(15):1593-602. [PubMed: 17646561]

14. Sekar, VJ.; Lefebvre, E.; Mariën, K., et al. Pharmacokinetic interaction between the HIV protease inhibitors TMC114 and saquinavir, in the presence of low-dose ritonavir. 44th Annual Meeting of the Infectious Disease Society of America; 2006 Oct 12-15; Toronto (ON). abstract no. 959

15. Sekar, VJ.; Lefebvre, E.; Boogaerts, G., et al. Pharmacokinetic interaction between the protease inhibitors TMC114 and lopinavir/ritonavir. 46th Interscience Conference on Antimicrobial Agents and Chemotherapy; 2006 Sep 27-30; San Francisco (CA). abstract no. A-367

16. Prezista ${ }^{\circledR}$ (darunavir): summary of product characteristics. London: Janssen-Cilag International NV; 2007.

17. Sekar VJ, Spinosa-Guzman S, De Paepe E, et al. Darunavir/ritonavir pharmacokinetics following coadministration with clarithromycin in healthy volunteers. J Clin Pharmacol 2008 Jan;48(1):605. [PubMed: 18094220]

18. Sekar VJ, Lefebvre E, De Paepe E, et al. Pharmacokinetic interaction between darunavir boosted with ritonavir and omeprazole or ranitidine in human immunodeficiency virus-negative healthy volunteers. Antimicrob Agents Chemother 2007 Mar;51(3):958-61. [PubMed: 17210768]

19. Abel, S.; Ridgway, C.; Hamlin, J., et al. An open, randomized, 2-way crossover study to investigate the effects of darunavir/ritonavir on the pharmacokinetics of maraviroc in healthy subjects. 8th International Workshop on Pharmacology of HIV Therapy; 2007 Apr 16-18; Budapest. abstract no. 55 
20. Pecini, R.; Vangeneugden, T.; Falcon, R., et al. Darunavir in combination with other medications: pharmacokinetic interactions. Presented at the American Conference for the Treatment of HIV (ACTHIV) 2007; 2007 May 31-Jun 3; Dallas (TX). poster no. S3-5

21. Sekar, V.; De Paepe, E.; Vangeneugden, T., et al. Absence of an interaction between the potent HIV protease inhibitor TMC114 and the fusion inhibitor enfuvirtide in the POWER 3 analysis. 7th International Workshop on Clinical Pharmacology of HIV Therapy; 2006 Apr 20-22; Lisbon. abstract no. 54

22. Sekar, VJ.; Lefebvre, E.; Mariën, K., et al. Pharmacokinetic interaction between the antiretroviral agents TMC114 and nevirapine, in the presence of low-dose ritonavir. 44th Annual Meeting of the Infectious Disease Society of America; 2006 Oct 12-15; Toronto (ON). abstract no. 956

23. Hoetelmans RM, Mariën K, De Pauw M, et al. Pharmacokinetic interaction between TMC114/ ritonavir and tenofovir disoproxil fumarate in healthy volunteers. Br J Clin Pharmacol 2007 Nov; 64(5):655-61. [PubMed: 17610528]

24. Boffito M, Winston A, Jackson A, et al. Pharmacokinetics and antiretroviral response to darunavir/ ritonavir and etravirine combination in patients with high-level viral resistance. AIDS 2007 Jul 11;21(11):1449-55. [PubMed: 17589191]

25. Intelence ${ }^{\mathrm{TM}}$ (etravirine) tablets: US prescribing information. Raritan (NJ): Tibotec Therapeutics, 2008 Jan. [2009 Feb 19]. [online]. Available from URL: http://www.intelence-info.com/intelence/assets/pdf/INTELENCE_PI.pdf

26. Schöller-Gyüre M, Kakuda TN, Sekar V, et al. Pharmacokinetics of darunavir/ritonavir and TMC125 alone and coadministered in HIV-negative volunteers. Antivir Ther 2007;12(5):789-96. [PubMed: 17713162]

27. Sekar VJ, De Pauw M, Mariën K, et al. Pharmacokinetic interaction between TMC114/r and efavirenz in healthy volunteers. Antivir Ther 2007;12(4):509-14. [PubMed: 17668559]

28. Lipitor ${ }^{\circledR}$ (atorvastatin calcium) tablets: US prescribing information. New York: Pfizer Inc; 2009 Feb [2009 Mar 27]. [online]. Available from URL: http://www.pfizer.com/files/products/uspi_lipitor.pdf

29. Chuck SK, Penzak SR. Risk-benefit of HMG-CoA reductase inhibitors in the treatment of HIV protease inhibitor-related hyperlipidaemia. Expert Opin Drug Saf 2002 May;1(1):5-17. [PubMed: 12904155]

30. Sekar, VJ.; Spinosa-Guzman, S.; Mariën, K., et al. Pharmacokinetic drug-drug interaction between the new HIV protease inhibitor darunavir (TMC114) and the lipid-lowering agent pravastatin. 8th International Workshop on Pharmacology of HIV Therapy; 2007 Apr 16-18; Budapest. abstract no. 55

31. Sekar, VJ.; Lefebvre, E.; Felicione, E., et al. Pharmacokinetic interaction between ethinyl estradiol, norethindrone and TMC114, a new protease inhibitor. 46th Interscience Conference on Antimicrobial Agents and Chemotherapy; 2006 Sep 27-30; San Francisco (CA). abstract no. A-368

32. HIV Insite. Antiretroviral management charts and tables. [2009 Feb 19]. [online]. Available from URL: http://www.hivinsite.com/InSite?page=ar-00-00-02

33. Sekar, V.; De Paepe, E.; De Marez, T., et al. Pharmacokinetic interaction between TMC114, a new protease inhibitor, and the selective serotonin reuptake inhibitors, paroxetine and sertraline. 8th International Congress on Drug Therapy for HIV; 2006 Nov 12-16; Glasgow. abstract no. P295

34. Carbon C, Poole MD. The role of newer macrolides in the treatment of community-acquired respiratory tract infection: a review of experimental and clinical data. J Chemother 1999 Apr; 11(2):107-18. [PubMed: 10326741]

35. Rodvold K. Clinical pharmacokinetics of clarithromycin. Clin Pharmacokinet 1999 Nov;37(5): 385-98. [PubMed: 10589373]

36. Ouellet D, Hsu A, Granneman GR, et al. Pharmacokinetic interaction between ritonavir and clarithromycin. Clin Pharmacol Ther 1998 Oct;64(4):355-62. [PubMed: 9797791]

37. Brophy DF, Israel DS, Pastor A, et al. Pharmacokinetic interaction between amprenavir and clarithromycin in healthy male volunteers. Antimicrob Agents Chemother 2000 Apr;44(4):978-84. [PubMed: 10722500] 
38. Boruchoff SE, Sturgill MG, Grasing KW, et al. The steady-state disposition of indinavir is not altered by the concomitant administration of clarithromycin. Clin Pharmacol Ther 2000 Apr;67(4): 351-9. [PubMed: 10801243]

39. Sekar, VJ.; Lefebvre, E.; De Pauw, M., et al. Pharmacokinetic interaction between TMC114 and ketoconazole, in the absence and presence of low-dose ritonavir. 44th Annual Meeting of the Infectious Disease Society of America; 2006 Oct 12-15; Toronto (ON). abstract no. 960

40. Nadler JP, Berger DS, Blick G, et al. TMC125-C223 Writing Group. Efficacy and safety of etravirine (TMC125) in patients with highly resistant HIV-1: primary 24-week analysis. AIDS 2007 Mar 30;21(6):F1-10. [PubMed: 17413684]

41. PubChem. Etravirine - compound summary (CID 193962). [2009 Feb 19]. [online]. Available from URL: http://pubchem.ncbi.nlm.nih.gov.libproxy.lib.unc.edu/summary/summary.cgi? cid $=193962 \&$ loc $=$ ec_rcs

42. Vingerhoets J, Azijn H, Fransen E, et al. TMC125 displays a high genetic barrier to the development of resistance: evidence from in vitro selection experiments. J Virol 2005 Oct;79(20): 12773-82. [PubMed: 16188980]

43. Andries K, Azijn H, Thielemans T, et al. TMC125, a novel next-generation nonnucleoside reverse transcriptase inhibitor active against nonnucleoside reverse transcriptase inhibitor-resistant human immunodeficiency virus type 1. Antimicrob Agents Chemother 2004 Dec;48(12):4680-6. [PubMed: 15561844]

44. Ramanathan, S.; West, S.; Kakuda, TN., et al. Lack of clinically relevant drug interactions between ritonavir-boosted elvitegravir and TMC125. 47th Interscience Conference on Antimicrobial Agents and Chemotherapy; 2007 Sep 17-20; Chicago (IL). abstract no. H-1049

45. Kakuda, TN.; Schöller-Gyüre, M.; Woodfall, B., et al. TMC125 in combination with other medications: summary of drug-drug interaction studies. 8th International Congress on Drug Therapy for HIV; 2006 Nov 12-16; Glasgow. abstract no. PL5.2

46. Kakuda, TN.; Kiser, JJ. Expert Opin Pharmacother; 7th International Workshop on Clinical Pharmacology of HIV Therapy; 20-22 April 2006; Lisbon, Portugal. 2006 Aug. p. 1519-33.

47. Israel, D.; Kakuda, TN.; Schöller-Gyüre, M., et al. TMC125 in combination with medications commonly used in HIV infection: summary of drug-drug interactions. American Conference for the Treatment of HIV (ACTHIV) 2007; 2007 May 31-Jun 3; Dallas (TX). poster no. S3-8

48. Schöller-Gyüre, M.; Kakuda, TN.; De Smedt, G., et al. Pharmacokinetics (PK) of TMC125 in QD and BID regimens in HIV-1 negative volunteers. 47th Interscience Conference on Antimicrobial Agents and Chemotherapy; 2007 Sep 17-20; Chicago (IL). abstract no. A-1427

49. Schöller-Gyüre, M.; Leemans, R.; Beets, G., et al. Effect of food on the oral bioavailability of the phase III formulation of TMC125. 7th International Workshop on Clinical Pharmacology of HIV Therapy; 2006 Apr 20-22; Lisbon. abstract no. 80

50. Schöller-Gyüre, M.; Kakuda, TN.; De Smedt, G., et al. Pharmacokinetics of TMC125 in HIVnegative volunteers with mild and moderate hepatic impairment. 47th Interscience Conference on Antimicrobial Agents and Chemotherapy; 2007 Sep 17-20; Chicago (IL). abstract no. A-1428

51. Etravirine: R165335, TMC 125, TMC-125, TMC125. Drugs R \& D 2006;7(6):367-73.

52. Hsu A, Granneman GR, Bertz RJ. Ritonavir: clinical pharmacokinetics and interactions with other anti-HIV agents. Clin Pharmacokinet 1998 Oct;35(4):275-91. [PubMed: 9812178]

53. Baede, P.; Piscitelli, S.; Graham, N., et al. Drug interactions with TMC125, a potent next generation NNRTI. 42nd Interscience Conference on Antimicrobial Agents and Chemotherapy; 2002 Sep 27-30; San Diego (CA). abstract no. A-1827

54. van der Lee MJ, Blenke AA, Rongen GA, et al. Interaction study of the combined use of paroxetine and fosamprenavir-ritonavir in healthy subjects. Antimicrob Agents Chemother 2007 Nov;51(11):4098-104. [PubMed: 17846135]

55. Schöller-Gyüre, M.; Woodfall, B.; Bollen, S., et al. Pharmacokinetics (PK) of amprenavir (APV) and TMC125 in HIV infected volunteers receiving TMC125 with fosamprenavir/ritonavir (fosAPV/RTV). 46th Interscience Conference on Antimicrobial Agents and Chemotherapy; 2006 Sep 27-30; San Francisco (CA). abstract no. A-370 
56. McCallister, S.; Sabo, J.; Galitz, L., et al. An open-label steady state investigation of the pharmacokinetics (PK) of tipranavir (TPV) and ritonavir (RTV) and their effects on cytochrome P-450 (3A4) activity in normal healthy volunteers (BI 1182.5). 9th Conference on Retroviruses and Opportunistic Infections; 2002 Feb 24-28; Seattle (WA). abstract no. 434

57. Vourvahis, M.; Dumond, J.; Patterson, K., et al. Effects of tipranavir/ritonavir on the activity of hepatic and intestinal cytochrome P450 3A4/5 and P-glycoprotein: implications for drug interactions. 14th Conference on Retroviruses and Opportunistic Infections; 2007 Feb 25-28; Los Angeles (CA). abstract no. 563

58. Schöller, M.; Kraft, M.; Hoetelmans, R., et al. Significant decrease in TMC125 exposures when co-administered with tipranavir boosted with ritonavir in healthy subjects. 13th Conference on Retroviruses and Opportunistic Infections; 2006 Feb 5-8; Denver (CO). abstract no. 583

59. Harris, M.; Zala, C.; Ramirez, S., et al. Pharmacokinetics and safety of adding TMC125 to stable regimens of saquinavir, lopinavir, ritonavir, and NRTI in HIV+ adults. 13th Conference on Retroviruses and Opportunistic Infections; 2006 Feb 5-8; Denver (CO). abstract no. 575b

60. Schöller, M.; Hoetelmans, R.; Bollen, S., et al. No significant interaction between TMC125 and didanosine (ddI) in healthy volunteers. 3rd IAS Conference on HIV Pathogenesis and Treatment; 2005 Jul 24-27; Rio de Janeiro. abstract no. WePe3.3C16

61. Schöller, M.; Hoetelmans, R.; Bollen, S., et al. No significant interaction between TMC125 and didanosine (ddI) in healthy volunteers. 6th International Workshop on Clinical Pharmacology of HIV Therapy; 2005 Apr 28-30; Quebec City (QC). abstract no. 29

62. Boffito, M.; Jackson, A.; Lamorde, M., et al. Evaluation of the pharmacokinetics and safety of etravirine administered once and twice daily following two weeks of treatment with efavirenz in healthy volunteers. 48th Interscience Conference on Antimicrobial Agents and Chemotherapy; 2008 Oct 25-28; Washington, DC. abstract no. H-4057

63. Anderson, MS.; Kakuda, TN.; Miller, JL., et al. Pharmacokinetic evaluation of non-nucleoside reverse transcriptase inhibitor (NNRTI) TMC125 and integrase inhibitor (InSTI) raltegravir (RAL) in healthy subjects. 4th IAS Conference on HIV Pathogenesis, Treatment and Prevention; 2007 Jul 22-25; Sydney. abstract no. TUPDB02

64. Schöller-Gyüre, M.; Kakuda, TN.; Bollen, S., et al. No pharmacokinetic interaction between TMC125 (etravirine; ETR) and paroxetine in HIV-negative volunteers. 11th European AIDS Conference; 2007 Oct 24-27; Madrid. abstract no. P4.3/01

65. Schöller-Gyüre, M.; De Smedt, G.; Vanaken, H., et al. TMC125 bioavailability is not affected by ranitidine and omeprazole. XVI International AIDS Conference; 2006 Aug 13-18; Toronto (ON). abstract no. TUPE0082

66. Eap CB, Cuendet C, Baumann P. Binding of d-methadone, l-methadone, and dl-methadone to proteins in plasma of healthy volunteers: role of the variants of $\alpha 1$-acid glycoprotein. Clin Pharmacol Ther 1990 Mar;47(3):338-46. [PubMed: 2311335]

67. Kharasch ED, Hoffer C, Whittington D, et al. Role of hepatic and intestinal cytochrome P450 3A and 2B6 in the metabolism, disposition, and miotic effects of methadone. Clin Pharmacol Ther 2004 Sep;76(3):250-69. [PubMed: 15371986]

68. Schöller-Gyüre M, van den Brink W, Kakuda T, et al. Pharmacokinetic and pharmacodynamic study of the concomitant administration of methadone and TMC125 in HIV-negative volunteers. J Clin Pharmacol 2008;48:322-9. [PubMed: 18195053]

69. Intelence ${ }^{\circledR}$ (etravirine) tablets: US prescribing information. Raritan (NJ): Tibotec Therapeutics; 2008 Jan [2009 Apr 1]. [online]. Available from URL: http://www.intelence-info.com/intelence/assets/pdf/INTELENCE_PI.pdf

70. Schöller-Gyüre, M.; Debroye, C.; Woodfall, B., et al. Pharmacokinetic interaction between TMC125 and clarithromycin. 44th Annual Meeting of the Infectious Disease Society of America; 2006 Oct 12-15; Toronto (ON). abstract no. 962

71. Schöller-Gyüre, M.; Woodfall, B.; Debroye, C., et al. Pharmacokinetic interaction between TMC125 and rifabutin. 44th Annual Meeting of the Infectious Disease Society of America; 2006 Oct 12-15; Toronto (ON). abstract no. 963

72. Schöller-Gyüre, M.; Kakuda, TN.; De Smedt, G., et al. Pharmacokinetic interaction between the non-nucleoside reverse transcriptase inhibitors (NNRTI) TMC125 and atorvastatin in HIV- 
negative volunteers. 4th IAS Conference on HIV Pathogenesis, Treatment and Prevention; 2007 Jul 22-25; Sydney. abstract no. WEPEA 106

73. PubChem. Rilpivirine - compound summary (CID 6451164). [2009 Feb 19]. [online]. Available from URL:

http://pubchem.ncbi.nlm.nih.gov.libproxy.lib.unc.edu/summary/summary.cgi? cid $=6451164 \&$ loc $=$ ec_rcs

74. Janssen PA, Lewi PJ, Arnold E, et al. In search of a novel anti-HIV drug: multidisciplinary coordination in the discovery of 4-[[4-[[4-[(1E)-2-cyanoethenyl]-2,6-dimethylphenyl]amino]-2pyrimidinyl]amino]benzonitrile (R278474, rilpivirine). J Med Chem 2005 Mar 24;48(6):1901-9. [PubMed: 15771434]

75. Goebel F, Yakovlev A, Pozniak AL, et al. Short-term antiviral activity of TMC278 - a novel NNRTI - in treatment-naïve HIV-1-infected subjects. AIDS 2006 Aug 22;20(13):1721-6. [PubMed: 16931936]

76. Hoetelmans, R.; Kestens, D.; Marièn, K., et al. Effect of food and multiple-dose pharmacokinetics of TMC278 as an oral tablet formulation: healthy volunteers. 3rd IAS Conference on HIV Pathogenesis and Treatment; 2005 Jul 24-27; Rio de Janeiro. abstract no. TuPe3.1B10

77. Van Heeswijk, R.; Hoetelmans, RMW.; Kestens, D., et al. The pharmacokinetic (PK) interaction between TMC278, a next generation non-nucleoside reverse transcriptase inhibitor (NNRTI), and once daily darunavir/ritonavir (DRV/r) in HIV-negative volunteers. 47th Interscience Conference on Antimicrobial Agents and Chemotherapy; 2007 Sep 17-20; Chicago (IL). abstract no. H-1042

78. Hoetelmans, R.; Kestens, D.; Stevens, M., et al. Pharmacokinetic interaction between the novel non-nucleoside reverse transcriptase inhibitor (NNRTI) TMC278 and tenofovir disoproxil fumarate (TDF) in healthy volunteers. 6th International Workshop on Clinical Pharmacology of HIV Therapy; 2005 Apr 28-30; Quebec City (QC). abstract no. 18

79. Van Heeswijk, RPG.; Hoetelmans, RMW.; Aharchi, F., et al. The pharmacokinetic (PK) interaction between atorvastatin (AVS) and TMC278, a next-generation non-nucleoside reverse transcriptase inhibitor (NNRTI), in HIV-negative volunteers. 11th European AIDS Conference; 2007 Oct 24-27; Madrid. abstract no. P4.3/04

80. Van Heeswijk, RP.; Hoetelmans, RM.; Kestens, D., et al. The pharmacokinetic interaction between ketoconazole and TMC278, an investigational non-nucleoside reverse transcriptase inhibitor in healthy, HIV-negative subjects. 16th International AIDS Conference; 2006 August 13-18; Toronto (ON). abstract no. TUPE0087

81. Schöller-Gyüre, M.; Debroye, C.; Vyncke, V., et al. The effects of CYP3A4 modulation on the pharmacokinetics of TMC278, an investigational, non-nucleoside reverse transcriptase inhibitor (NNRTI). 7th International Workshop on Clinical Pharmacology of HIV Therapy; 2006 Apr 20-22; Lisbon. abstract no. 45

82. Van Heeswijk, R.; Hoetelmans, R.; Kestens, D., et al. The pharmacokinetic (PK) interaction between famotidine and TMC278, a next generation non-nucleoside reverse transcriptase inhibitor (NNRTI), in HIV-negative volunteers. 4th IAS Conference on HIV Pathogenesis, Treatment and Prevention; 2007 July 22-25; Sydney. abstract no. TUPDB01

83. PubChem. Maraviroc - compound summary (CID 3002977). [2009 Feb 19]. [online]. Available from URL:

http://pubchem.ncbi.nlm.nih.gov.libproxy.lib.unc.edu/summary/summary.cgi? cid $=3002977 \&$ loc $=$ ec_rcs

84. Dorr P, Westby M, Dobbs S, et al. Maraviroc (UK-427,857), a potent, orally bioavailable, and selective small-molecule inhibitor of chemokine receptor CCR5 with broad-spectrum anti-human immunodeficiency virus type 1 activity. Antimicrob Agents Chemother 2005 Nov;49(11):472132. [PubMed: 16251317]

85. Hyland, R.; Jones, B.; Muirhead, G. In vitro assessment of the CYP-based drug-drug interaction potential of UK-427,857. 5th International Workshop on the Clinical Pharmacology of HIV Therapy; 2004 Mar 11-13; Rome. poster no. 5.9

86. Abel, S.; Russell, D.; Ridgway, C., et al. The effect of CCR5 antagonist UK-427,857, on the pharmacokinetics of CYP3A4 substrates in healthy volunteers. 5th International Workshop on the Clinical Pharmacology of HIV Therapy; 2004 Mar 11-13; Rome. poster no. 5.7 
87. Abel S, Russell D, Whitlock LA, et al. Effect of maraviroc on the pharmacokinetics of midazolam, lamivudine/zidovudine, and ethinyloestradiol/levonorgestrel in healthy volunteers. Br J Clin Pharmacol 2008 Apr;65(Suppl. 1):19-26. [PubMed: 18333862]

88. Walker DK, Abel S, Comby P, et al. Species differences in the disposition of the CCR5 antagonist, UK-427,857, a new potential treatment for HIV. Drug Metab Dispos 2005 Apr;33(4):587-95. [PubMed: 15650075]

89. Pfizer Inc. Maraviroc tablets NDA 22-128: Antiviral Drugs Advisory Committee briefing document, April 24, 2007. [2009 Feb 19]. [online]. Available from URL: http://www.fda.gov/OHRMS/DOCKETS/AC/07/briefing/2007-4283b1-01-Pfizer.pdf

90. Selzentry ${ }^{\circledR}$ (maraviroc) tablets: US prescribing information. New York: Pfizer Labs; 2008 Nov [2009 Mar 27]. [online]. Available from URL: http://media.pfizer.com/files/products/uspi_maraviroc.pdf

91. Abel S, Russell D, Whitlock LA, et al. Assessment of the absorption, metabolism and absolute bioavailability of maraviroc in healthy male subjects. Br J Clin Pharmacol 2008 Apr;65(Suppl. 1): 60-7. [PubMed: 18333867]

92. Abel, S.; Van der Ryst, E.; Muirhead, GJ., et al. Pharmacokinetics of single and multiple oral doses of UK-427,857 - a novel CCR5 antagonist in healthy volunteers. 10th Conference on Retroviruses and Opportunistic Infections; 2003 Feb 10-14; Boston (MA). abstract no. 547

93. Abel S, van der Ryst E, Rosario MC, et al. Assessment of the pharmacokinetics, safety and tolerability of maraviroc, a novel CCR5 antagonist, in healthy volunteers. Br J Clin Pharmacol 2008 Apr;65(Suppl. 1):5-18. [PubMed: 18333861]

94. Russell, D.; Ridgway, C.; Taylor-Worth, R., et al. Pharmacokinetics special populations and toxicity comparison of the pharmacokinetics of maraviroc (UK-427,857) in healthy Asian and Caucasian subjects. 6th International Workshop on Clinical Pharmacology of HIV Therapy; 2005 Apr 28-30; Quebec City (QC). abstract no. 41

95. Abel, S.; Ridgway, C.; Hamlin, J., et al. An open, parallel group study to compare the pharmacokinetics, safety and toleration of a single oral dose of maraviroc in subjects with mild and moderate hepatic impairment with subjects with normal hepatic function. 8th International Workshop on Pharmacology of HIV Therapy; 2007 Apr 16-18; Budapest. abstract no. 8

96. Muirhead, G.; Pozniak, A.; Gazzard, B., et al. A novel probe drug interaction study to investigate the effect of selected ARV combinations on the pharmacokinetics of a single oral dose of UK-427,857 in HIV +ve subjects. 12th Conference on Retroviruses and Opportunistic Infections; 2005 Apr 22-25; Boston (MA). abstract no. 663

97. Pozniak AL, Boffito M, Russell D, et al. A novel probe drug interaction study to investigate the effect of selected antiretroviral combinations on the pharmacokinetics of a single oral dose of maraviroc in HIV-positive subjects. Br J Clin Pharmacol 2008 Apr;65(Suppl. 1):54-9. [PubMed: 18333866]

98. Abel, S.; Russell, C.; Ridgway, C., et al. The effect of CYP3A4 inhibitors on the pharmacokinetics of CCR5 antagonist UK-427,857, in healthy volunteers. 5th International Workshop on the Clinical Pharmacology of HIV Therapy; 2004 Mar 11-13; Rome. poster no. 5.8

99. Abel S, Russell D, Taylor-Worth RJ, et al. Effects of CYP3A4 inhibitors on the pharmacokinetics of maraviroc in healthy volunteers. Br J Clin Pharmacol 2008 Apr;65(Suppl. 1):27-37. [PubMed: 18333863]

100. Muirhead, G.; Ridgway, C.; Leahy, D., et al. A study to investigate the combined coadministration of P450 CYP3A4 inhibitors and inducers on the pharmacokinetics of the novel CCR5 inhibitor UK-427,857. 7th International Congress on Drug Therapy for HIV; 2004 Nov 14-18; Glasgow. abstract no. P284

101. Abel S, Jenkins TM, Whitlock LA, et al. Effects of CYP3A4 inducers with and without CYP3A4 inhibitors on the pharmacokinetics of maraviroc in healthy volunteers. Br J Clin Pharmacol 2008 Apr;65(Suppl. 1):38-46. [PubMed: 18333864]

102. Abel, S.; Taylor-Worth, R.; Ridgway, C., et al. Effect of boosted tipranavir on the pharmacokinetics of maraviroc (UK 427,857) in healthy volunteers. 10th European AIDS Conference; 2005 Nov 17-20; Dublin. abstract no. LBPE4.3/15 
103. Muirhead, G.; Abel, S.; Russell, D., et al. An investigation of the effects of atazanavir and ritonavir boosted atazanavir on the pharmacokinetics of the novel CCR5 inhibitor UK-427,857. 7th International Congress on Drug Therapy for HIV; 2004 Nov 14-18; Glasgow. abstract no. P283

104. Russell, D.; Abel, S.; Hackman, F., et al. The effect of maraviroc (UK-427,857) on the pharmacokinetics of 3TC/AZT (Combivir ${ }^{\mathrm{TM}}$ ) in healthy subjects. 6th International Workshop on Clinical Pharmacology of HIV Therapy; 2005 Apr 28-30; Quebec City (QC). abstract no. 30

105. Jenkins, T.; Abel, S.; Russell, D., et al. The effect of $\mathrm{P} 450$ inducers on the pharmacokinetics of CCR5 antagonist UK-427,857, in healthy volunteers. 5th International Workshop on the Clinical Pharmacology of HIV Therapy; 2004 Mar 11-13; Rome. poster no. 5.4

106. Davis, J.; Schöller-Gyüre, M.; Kakuda, TN., et al. An open, randomized, two-period, crossover study in 2 cohorts to investigate the effect of steady-state TMC125 and the combination of TMC125/darunavir/ritonavir on the steady-state pharmacokinetics of oral maraviroc in healthy subjects. 11th European AIDS Conference/EACS; 2007 Oct 24-27; Madrid. abstract no. P4.3/02

107. Ramanathan, S.; West, S.; Abel, S., et al. Pharmacokinetics of coadministered ritonavir-boosted elvitegravir plus maraviroc. 47th Interscience Conference on Antimicrobial Agents and Chemotherapy; 2007 Sep 17-20; Chicago (IL). abstract no. H-1050

108. Andrews, E.; Glue, P.; Labadie, R., et al. A pharmacokinetic (PK) study to evaluate an interaction between maraviroc (MVC) and raltegravir (RAL) in healthy adults. 48th Interscience Conference on Antimicrobial Agents and Chemotherapy/IDSA 46th Annual Meeting; 2008 Oct 25-28; Washingtion, DC. abstract no. H-4055

109. Panel on Antiretroviral Guidelines for Adults and Adolescents, US Department of Health and Human Services. Guidelines for the use of antiretroviral agents in HIV-1-infected adults and adolescents. [2009 Mar 27]. [online]. Available from URL: http://aidsinfo.nih.gov/contentfiles/AdultandAdolescentGL.pdf

110. Strizki JM, Tremblay C, Xu S, et al. Discovery and characterization of vicriviroc (SCH 417690), a CCR5 antagonist with potent activity against human immunodeficiency virus type 1 . Antimicrob Agents Chemother 2005 Dec;49(12):4911-9. [PubMed: 16304152]

111. Ghosal A, Ramanathan R, Yuan Y, et al. Identification of human liver cytochrome P450 enzymes involved in biotransformation of vicriviroc, a CCR5 receptor antagonist. Drug Metab Dispos 2007 Dec;35(12):2186-95. [PubMed: 17827338]

112. Li C, Keung A, Morrison RA, et al. Vicriviroc, a novel CCR5 inhibitor, is not a P-glycoprotein substrate in vitro. Retrovirology 2005;2(Suppl. 1):P158.

113. Schürmann D, Fätkenheuer G, Reynes J, et al. Antiviral activity, pharmacokinetics and safety of vicriviroc, an oral CCR5 antagonist, during 14-day monotherapy in HIV-infected adults. AIDS 2007 Jun 19;21(10):1293-9. [PubMed: 17545705]

114. Keung, A.; Sansone, A.; Caceres, M., et al. Effect of food on bioavailability of SCH 417690 in healthy volunteers. 45th Interscience Conference on Antimicrobial Agents and Chemotherapy; 2005 Dec 16-19; Washington, DC. abstract no. A-1200

115. Sansone, A.; Seiberling, M.; Kraan, M., et al. Similar increase in SCH 417690 plasma exposure with coadministration of varying doses of ritonavir in healthy volunteers. 6th International Workshop on Clinical Pharmacology of HIV Therapy; 2005 Apr 28-30; Quebec City (QC). abstract no. 78

116. Sansone, A.; Keung, A.; Tetteh, E., et al. Pharmacokinetics of vicriviroc are not affected in combination with five different protease inhibitors boosted by ritonavir. 13th Conference on Retroviruses and Opportunistic Infections; 2006 Feb 5-8; Denver (CO). abstract no. 582

117. Sansone, A.; Saltzman, M.; Rosenberg, M., et al. Pharmacokinetics of new drugs pharmacokinetics of SCH 417690 administered alone or in combination with ritonavir or lopinavir/ritonavir. 6th International Workshop on Clinical Pharmacology of HIV Therapy; 2005 Apr 28-30; Quebec City (QC). abstract no. 83

118. Sansone-Parsons, A.; Keung, A.; Caceres, M., et al. The addition of tipranavir has no impact on the pharmacokinetics of vicriviroc when coadministered with a potent CYP3A4 inhibitor such as ritonavir. 8th International Workshop on Pharmacology of HIV Therapy; 2007 Apr 16-18; Budapest. abstract no. 57 
119. Sansone, A.; Guillaume, M.; Kraan, M., et al. The pharmacokinetics of SCH 417690 when administered alone and in combination with lamivudine/zidovudine. 6th International Workshop on Clinical Pharmacology of HIV Therapy; 2005 Apr 28-30; Quebec City (QC). abstract no. 84

120. Sansone, A.; Guillaume, M.; Kraan, M., et al. Pharmacokinetics of SCH 417690 administered alone or in combination with tenofovir. 6th International Workshop on Clinical Pharmacology of HIV Therapy; 2005 Apr 28-30; Quebec City (QC). abstract no. 85

121. Sansone, A.; Saltzman, M.; Rosenberg, M., et al. Pharmacokinetics of SCH 417690 administered alone or in combination with ritonavir and efavirenz in healthy volunteers. 6th International Workshop on Clinical Pharmacology of HIV Therapy; 2005 Apr 28-30; Quebec City (QC). abstract no. 79

122. Shin, N.; Solomon, K.; Wang, KH., et al. INCB 9471 is a non-competitive small molecule antagonist of CCR5. 47th Interscience Conference on Antimicrobial Agents and Chemotherapy; 2007 Sep 17-20; Chicago (IL). abstract no. H-1032

123. Cohen, C.; DeJesus, E.; Mills, A., et al. Potent antiretroviral activity of the once-daily CCR5 antagonist INCB009471 over 14 days of monotherapy. 4th IAS Conference on HIV Pathogenesis, Treatment and Prevention; 2007 July 22-25; Sydney. abstract no. TUAB106

124. Troy, S.; Emm, T.; Yeleswaram, S., et al. Single and multiple dose pharmacokinetics of INCB009471: a potent antagonist of CCR5 co-receptor. 47th Interscience Conference on Antimicrobial Agents and Chemotherapy; 2007 Sep 17-20; Chicago (IL). abstract no. H-1034

125. Troy, S.; Emm, T.; Yeleswaram, S., et al. Effect of ritonavir on the pharmacokinetics of INCB009471: a potent antagonist of the CCR5 co-receptor. 47th Interscience Conference on Antimicrobial Agents and Chemotherapy; 2007 Sep 17-20; Chicago (IL). abstract no. H-1035

126. Isentress ${ }^{\mathrm{TM}}$ (raltegravir) tablets: US prescribing information. Whitehouse Station (NJ): Merck \& Co., Inc.; 2009 Jan [2009 Mar 27]. [online]. Available from URL: http://www.merck.com/product/usa/pi_circulars/i/isentress/isentress_pi.pdf

127. Roquebert B, Damond F, Collin G, et al. French ANRS HIV-2 Cohort (ANRS CO 05 VIH-2). Polymorphism of HIV-2 integrase gene and in vitro phenotypic susceptibility of HIV-2 clinical isolates to integrase inhibitors: raltegravir and elvitegravir. Antivir Ther 2007;12:S92. abstract no. 83 .

128. Kassahun K, McIntosh I, Cui D, et al. Metabolism and disposition in humans of raltegravir (MK-0518), an anti-AIDS drug targeting the human immunodeficiency virus 1 integrase enzyme. Drug Metab Dispos 2007 Sep;9(35):1657-63. [PubMed: 17591678]

129. Petry, AS.; Wenning, LA.; Laethem, M., et al. Safety, tolerability, and pharmacokinetics after single and multiple doses of MK-0518 in healthy subjects. 46th Interscience Conference on Antimicrobial Agents and Chemotherapy; 2006 Sep 27-30; San Francisco (CA). abstract no. A-376

130. Markowitz M, Morales-Ramirez JO, Nguyen BY, et al. Antiretroviral activity, pharmacokinetics, and tolerability of MK-0518, a novel inhibitor of HIV-1 integrase, dosed as monotherapy for 10 days in treatment-naïve HIV-1-infected individuals. J Acquir Immune Defic Syndr 2006 Dec 15;43(5):509-15. [PubMed: 17133211]

131. Wenning, L.; Anderson, M.; Petry, A., et al. Raltegravir (RAL) dose proportionality and effect of food. 47th Interscience Conference on Antimicrobial Agents and Chemotherapy; 2007 Sep 17-20; Chicago (IL). abstract no. H-1046

132. Iwamoto M, Hanley W, Petry A, et al. Lack of a clinically important effect of moderate hepatic insufficiency and severe renal insufficiency on raltegravir pharmacokinetics. Antimicrob Agents Chemother. 2009 Feb 17; Epub.

133. Vourvahis M, Kashuba AD. Mechanisms of pharmacokinetic and pharmacodynamic drug interactions associated with ritonavir-enhanced tipranavir. Pharmacotherapy 2007 Jun;27(6):888909. [PubMed: 17542771]

134. Iwamoto, M.; Wenning, LA.; Petry, AS., et al. Minimal effect of ritonavir (RTV) and efavirenz (EFV) on the pharmacokinetics (PK) of Mk-0518. 46th Interscience Conference on Antimicrobial Agents and Chemotherapy; 2006 Sep 27-30; San Francisco (CA). abstract no. A-373 
135. Wenning, LA.; Hanley, H.; Stone, J., et al. Effect of tipranavir + ritonavir TPV + RTV on pharmacokinetics of MK-0518. 46th Interscience Conference on Antimicrobial Agents and Chemotherapy; 2006 Sep 27-30; San Francisco (CA). abstract no. A-374

136. Merck Research Laboratories. FDA Antiviral Drugs Advisory Committee Meeting: Isentress ${ }^{\mathrm{TM}}$ (raltegravir) $400 \mathrm{mg}$ for treatment of HIV (NDA 22-145). Briefing document (background package). [2009 Feb 19]. [online]. Available from URL: http://www.fda.gov/ohrms/dockets/ac/07/briefing/2007-4314b1-01-Merck.pdf

137. Kumar, P.; Cooper, D.; Steigbigel, R., et al. Efficacy of raltegravir, an HIV integrase inhibitor, in combination with regimens containing-efuvirtide, darunavir, or tipranavir in patients with tripleclass resistant virus: combined results from BENCHMRK-1 and BENCHMRK-2. 11th European AIDS Conference/EACS; 2007 Oct 24-27; Madrid. abstract no. P7.2/06

138. Wenning, LA.; Friedman, E.; Kost, JT., et al. Lack of a significant drug interaction between MK-0518 and tenofovir disoproxil fumarate (TDF). 46th Interscience Conference on Antimicrobial Agents and Chemotherapy; 2006 Sep 27-30; San Francisco, (CA). abstract no. A-375

139. Iwamoto M, Wenning L, Petry A, et al. Minimal effects of ritonavir and efavirenz on the pharmacokinetics of raltegravir. Antimicrob Agents Chemother 2008;52(12):4338-43. [PubMed: 18838589]

140. Iwamoto M, Kassahun K, Troyer MD, et al. Lack of a pharmacokinetic effect of raltegravir on midazolam: in vitro/in vivo correlation. J Clin Pharmacol 2008 Feb;48(2):209-14. [PubMed: 18077730]

141. Iwamoto, M.; Wenning, LA.; Liou, SY., et al. Rifampin (RIF) modestly reduces plasma levels of MK-0518. 8th International Congress on Drug Therapy for HIV; 2006 Nov 12-16; Glasgow. abstract no. P299

142. Anderson, MS.; Wenning, LA.; Moreau, A., et al. Effect of raltegravir (RAL) on the pharmacokinetics (PK) of oral contraceptives. 47th Interscience Conference on Antimicrobial Agents and Chemotherapy; 2007 Sep 17-20; Chicago. abstract no. A-1425

143. PubChem. JTK 303 [elvitegravir] - compound summary (CID 5277135). [2009 Feb 19]. [online]. Available from URL:

http://pubchem.ncbi.nlm.nih.gov.libproxy.lib.unc.edu/summary/summary.cgi?

cid $=5277135 \& l o c=e c \_r c s$

144. Ramanathan S, Shen G, Hinkle J, et al. Pharmacokinetics of coadministered ritonavir-boosted elvitegravir and zidovudine, didanosine, stavudine, or abacavir. J Acquir Immune Defic Syndr 2007 Oct 1;46(2):160-6. [PubMed: 17693892]

145. DeJesus E, Berger D, Markowitz M, et al. for the 183-0101 Study Team. Antiviral activity, pharmacokinetics, and dose response of the HIV-1 integrase inhibitor GS-9137 (JTK-303) in treatment-naïve and treatment-experienced patients. J Acquir Immune Defic Syndr 2006 Sep; 43(1):1-5. [PubMed: 16936557]

146. Kawaguchi, I.; Ishikawa, T.; Ishibashi, M., et al. Safety and pharmacokinetics of single oral dose of JTK-303/GS-9137, a novel HIV integrase inhibitor, in healthy volunteers. 13th Conference on Retroviruses and Opportunistic Infections; 2006 Feb 5-9; San Francisco (CA).

147. Mathias, A.; Hinkle, J.; Enejosa, J., et al. Lack of pharmacokinetic interaction between ritonavirboosted GS-9137 (elvitegravir) and tipranavir/r. 4th IAS Conference on HIV Pathogenesis, Treatment and Prevention; 2007 Jul 22-25; Sydney. abstract no. TUPDB06

148. Mathias, A.; Shen, G.; Enejosa, J., et al. Lack of pharmacokinetic interaction between ritonavirboosted GS-9137 (elvitegravir) and darunavir/r. 4th IAS Conference on HIV Pathogenesis, Treatment and Prevention; 2007 Jul 22-25; Sydney. abstract no. TUPDB03

149. Ziagen ${ }^{\circledR}$ (abacavir sulphate) tablets and oral solution: US prescribing information. Research Triangle Park (NC): GlaxoSmithKline; 2008 Jul [2009 Mar 27]. [online]. Available from URL: http://us.gsk.com/products/assets/us_ziagen.pdf

150. Retrovir (zidovudine) IV infusion: US prescribing information. Research Triangle Park (NC): GlaxoSmithKline, 2006. [2009 Feb 19]. [online]. Available from URL: http://us.gsk.com/products/assets/us_retrovir_injection.pdf 
151. Ramanathan, S.; Skillington, J.; Plummer, A., et al. Lack of clinically relevant drug-drug interaction between ritonavir-boosted GS-9137 (GS-9137/r) and emtricitabine (FTC)/tenofovir disoproxil fumarate (TDF). XVI International AIDS Conference; 2006 Aug 13-18; Toronto (ON). abstract no. TUPE0080

152. Ramanathan, S.; Lagan, K.; Plummer, A., et al. Pharmacokinetic evaluation of drug interactions with ritonavir-boosted HIV integrase inhibitor GS-9137 (elvitegravir) and acid-reducing agents. 8th International Workshop on Clinical Pharmacology of HIV Therapy; 2007 Apr 16-18; Budapest. abstract no. 69

153. Li F, Goila-Gaur R, Salzwedel K, et al. PA-457: a potent HIV inhibitor that disrupts core condensation by targeting a late step in Gag processing. Proc Natl Acad Sci U S A 2003 Nov 11;100(23):13555-60. [PubMed: 14573704]

154. Martin DE, Blum R, Wilton J, et al. Safety and pharmacokinetics of bevirimat (PA-457), a novel inhibitor of human immunodeficiency virus maturation, in healthy volunteers. Antimicrob Agents Chemother 2007 Sep;51(9):3063-6. [PubMed: 17576843]

155. Martin, DE.; Smith, P.; Wild, CT., et al. In vitro and in vivo disposition of PA-457, a novel inhibitor of HIV-1 maturation. XV International AIDS Conference; 2004 Jul 11-16; Bangkok. abstract no. WePeA5644

156. Martin DE, Blum R, Doto J, et al. Multiple-dose pharmacokinetics and safety of bevirimat, a novel inhibitor of HIV maturation, in healthy volunteers. Clin Pharmacokinet 2007;46(7):589_ 98. [PubMed: 17596104]

157. Martin, DE.; Smith, P.; Goila-Gaur, R., et al. Determinants of activity, in vitro metabolism and in vivo disposition of the novel maturation inhibitor PA-457. 11th Conference on Retroviruses and Opportunistic Infections; 2004 Feb 8-11; San Francisco (CA). abstract no. 545

158. Smith, P.; Forrest, A.; Beatty, G., et al. Pharmacokinetics/pharmacodynamics of PA-457 in a 10day multiple dose monotherapy trial in HIV infected patients. 13th Conference on Retroviruses and Opportunistic Infections; 2006 Feb 5-8; Denver (CO). abstract no. 52

159. Martin, D.; Galbraith, H.; Ellis, C., et al. Minimal effect of ritonavir (RTV) on the pharmacokinetics (PK) of bevirimat (BVM) in healthy volunteers. 4th IAS Conference on HIV Pathogenesis, Treatment and Prevention; 2007 Jul 22-25; Sydney. abstract no. WEPEB015

160. Martin, DE.; Gailbraith, H.; Schettler, J., et al. Lack of a PK/PD interaction between PA-457 and atazanavir (ATV) in healthy volunteers. 46th Interscience Conference on Antimicrobial Agents and Chemotherapy; 2006 Sep 27-30; San Francisco (CA). abstract no. A-377

161. de Béthune, M-P.; Andries, K.; Azijn, H., et al. TMC278, a new potent NNRTI, with an increased barrier to resistance and good pharmacokinetic profile. 12th Conference on Retroviruses and Opportunistic Infections; 2005 Feb 22-25; Boston (MA). abstract no. 556

162. Petry, AS.; Hanley, WD.; Silk, G., et al. Effect of severe renal insufficiency on raltegravir (RAL) pharmacokinetics. 47th Interscience Conference on Antimicrobial Agents and Chemotherapy; 2007 Sep 17-20; Chicago (IL). abstract no. A-1424 
a Darunavir
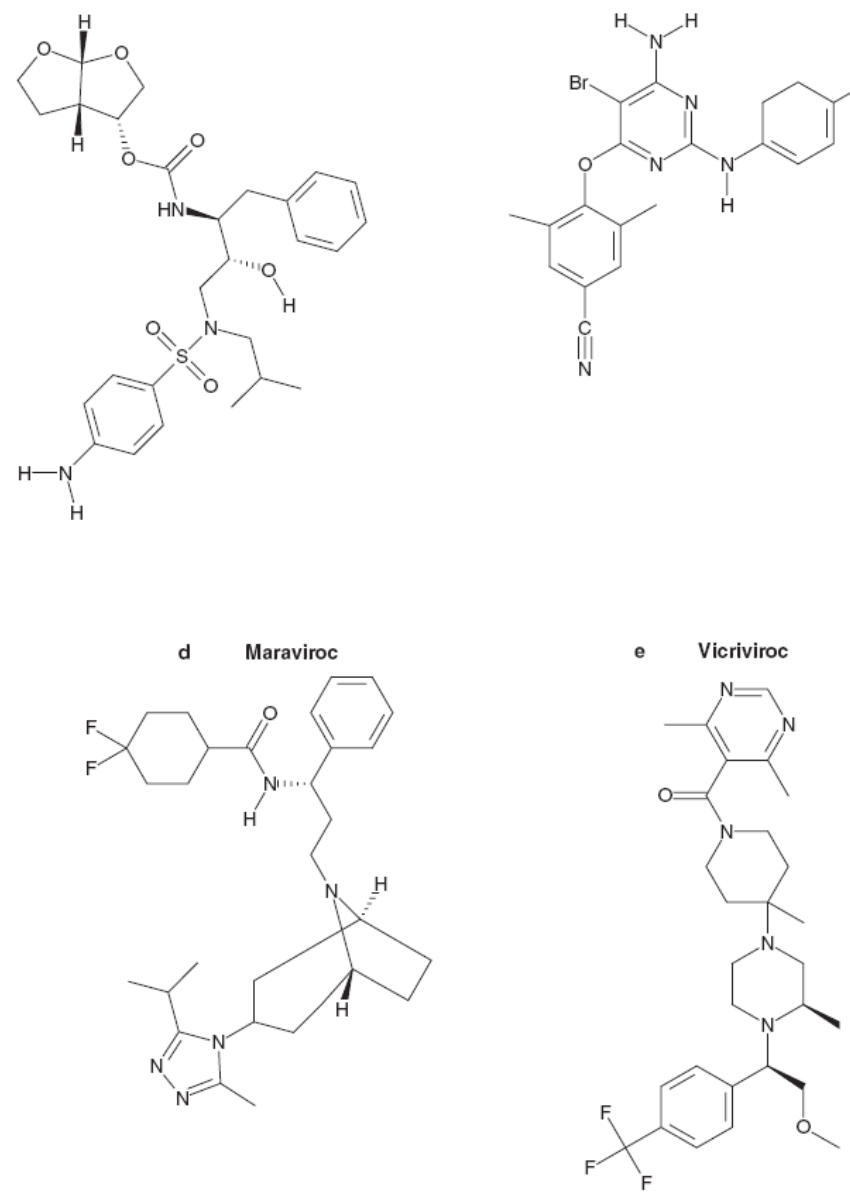

g

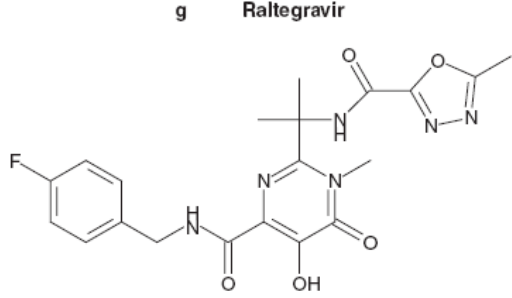

h Elvitegravir

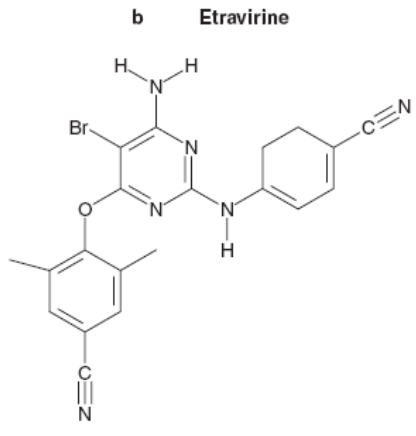

c Rilpivirine
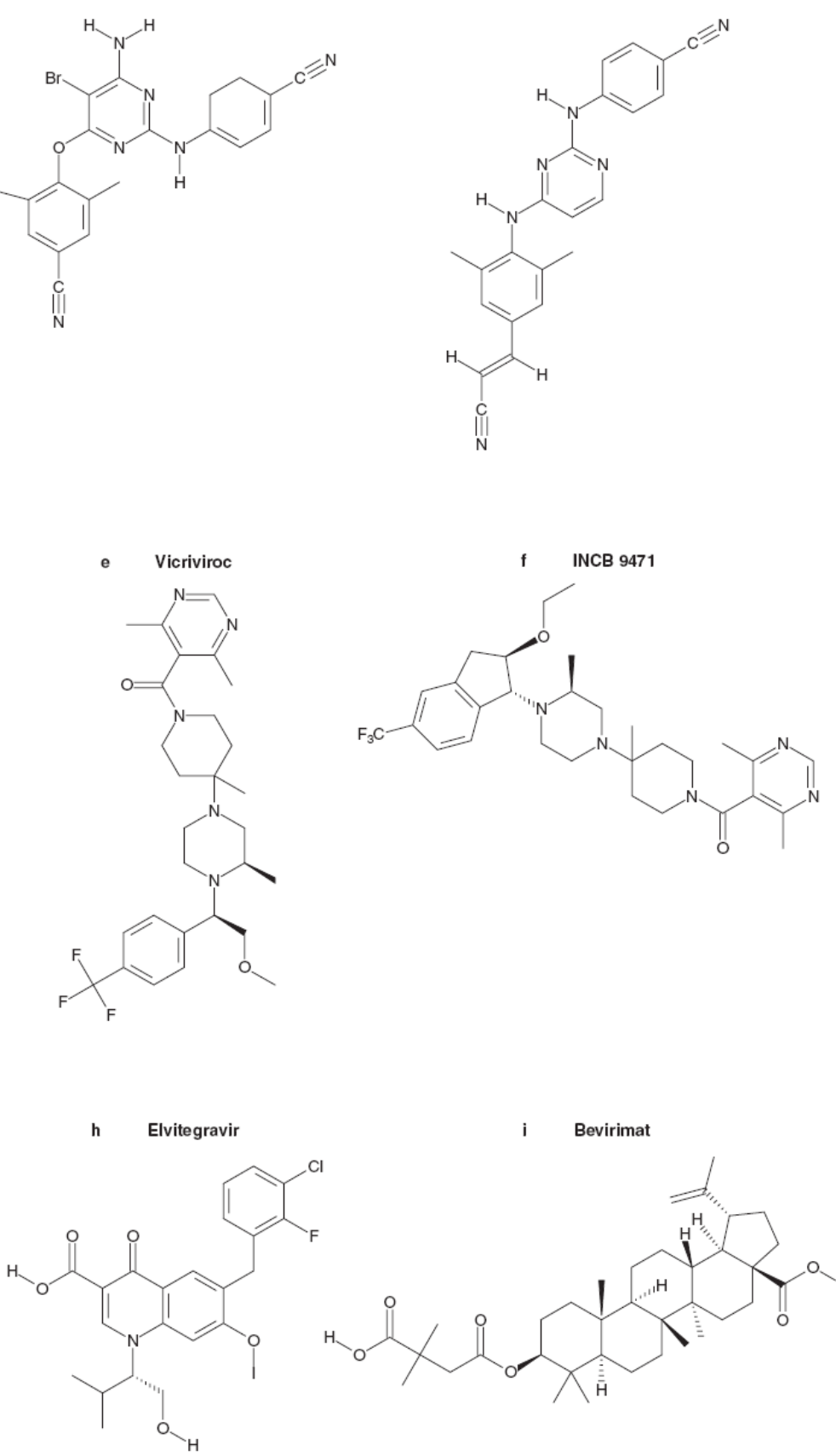

Bevirimat

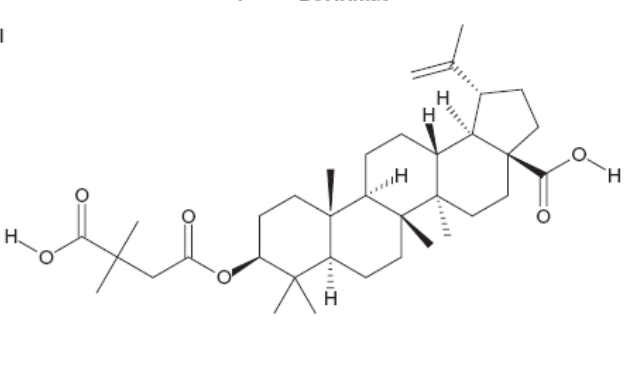

Fig. 1.

Chemical structures of (a) darunavir, (b) etravirine, $(\mathbf{c})$ rilpivirine, $(\mathbf{d})$ maraviroc, $(\mathbf{e})$ vicriviroc, (f) INCB 9471 (g) raltegravir, (h) elvitegravir and (i) bevirimat. 


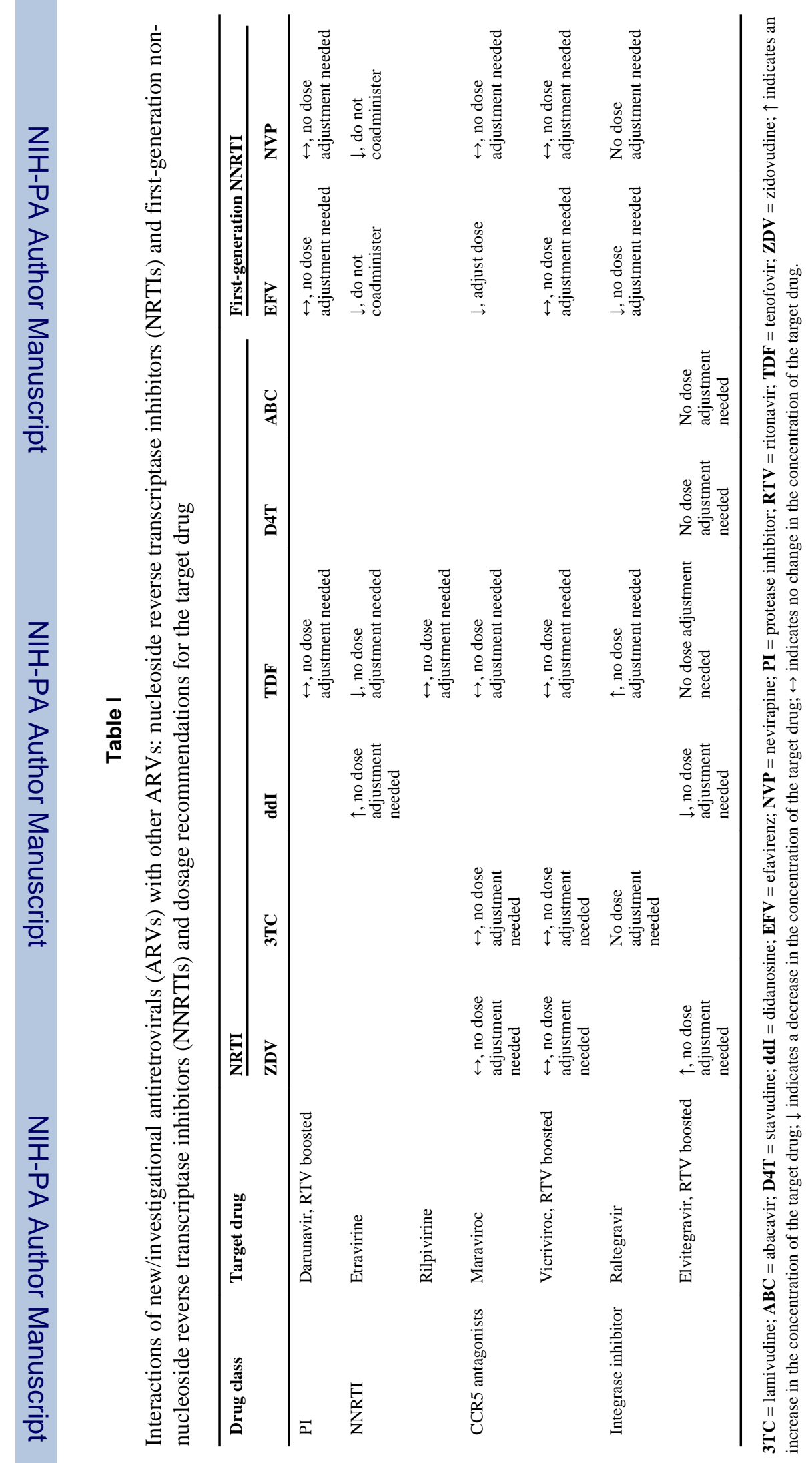




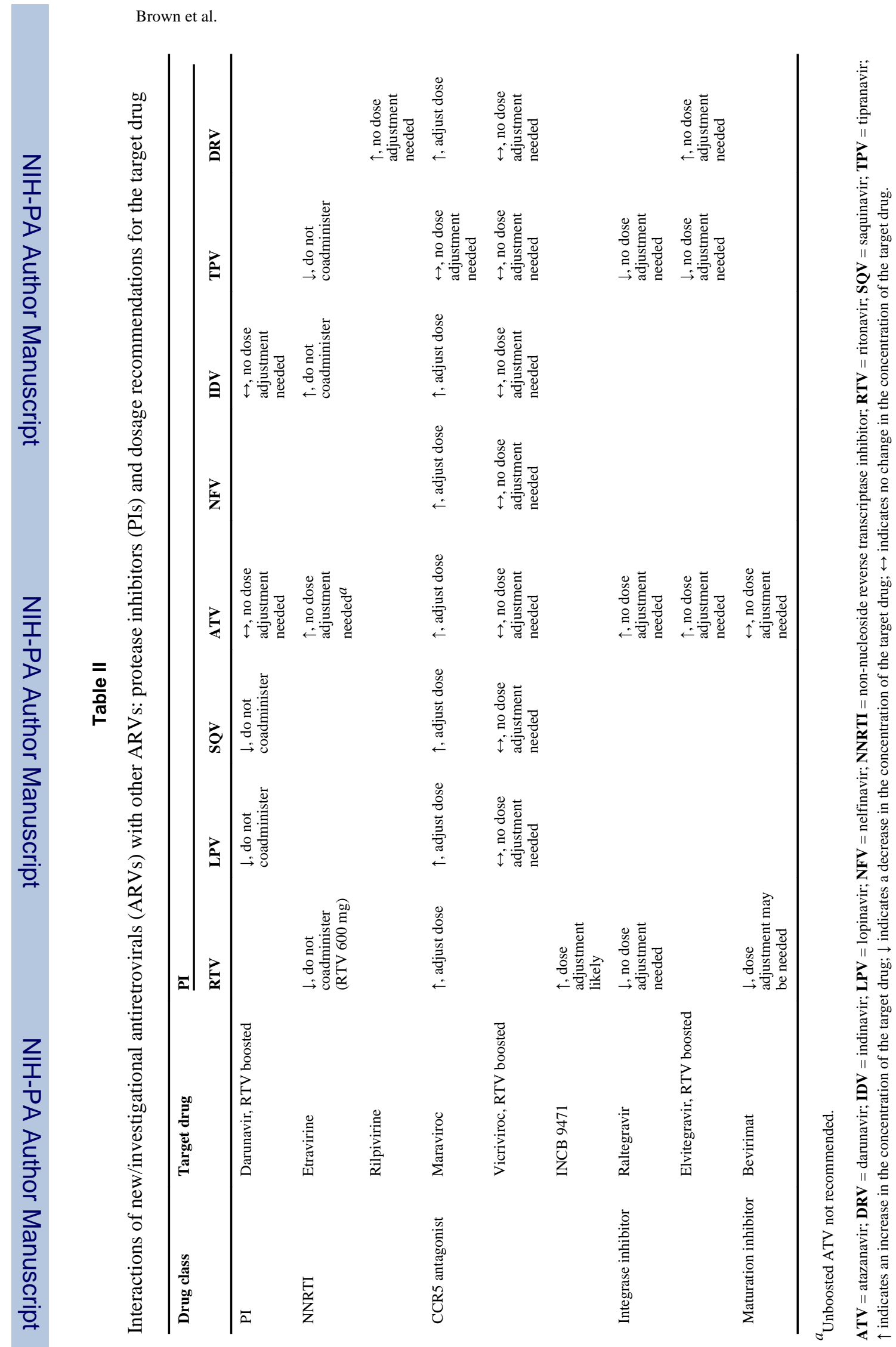

Clin Pharmacokinet. Author manuscript; available in PMC 2010 April 21. 
Table III

Interactions of new/investigational antiretrovirals (ARVs) with other ARVs: second-generation nonnucleoside reverse transcriptase inhibitors (NNRTIs) and CCR5 antagonists

\begin{tabular}{|c|c|c|c|}
\hline \multirow[t]{2}{*}{ Drug class } & \multirow[t]{2}{*}{ Target drug } & \multirow{2}{*}{$\begin{array}{l}\text { Second-generation NNRTI } \\
\text { etravirine }\end{array}$} & \multirow{2}{*}{$\begin{array}{l}\text { CCR5 antagonist } \\
\text { maraviroc }\end{array}$} \\
\hline & & & \\
\hline PI & Darunavir, RTV boosted & $\leftrightarrow$, no dose adjustment needed & $\leftrightarrow$, no dose adjustment needed \\
\hline NNRTI & Etravirine & & $\leftrightarrow$, no dose adjustment needed \\
\hline CCR5 antagonist & Maraviroc & $\downarrow$, adjust dose & \\
\hline \multirow[t]{2}{*}{ Integrase inhibitor } & Raltegravir & $\downarrow$, no dose adjustment needed & \\
\hline & Elvitegravir, RTV boosted & $\leftrightarrow$, no dose adjustment needed & $\leftrightarrow$, no dose adjustment needed \\
\hline
\end{tabular}

PI = protease inhibitor; RTV = ritonavir; $\uparrow$ indicates an increase in the concentration of the target drug; $\downarrow$ indicates a decrease in the concentration of the target drug; $\leftrightarrow$ indicates no change in the concentration of the target drug. 


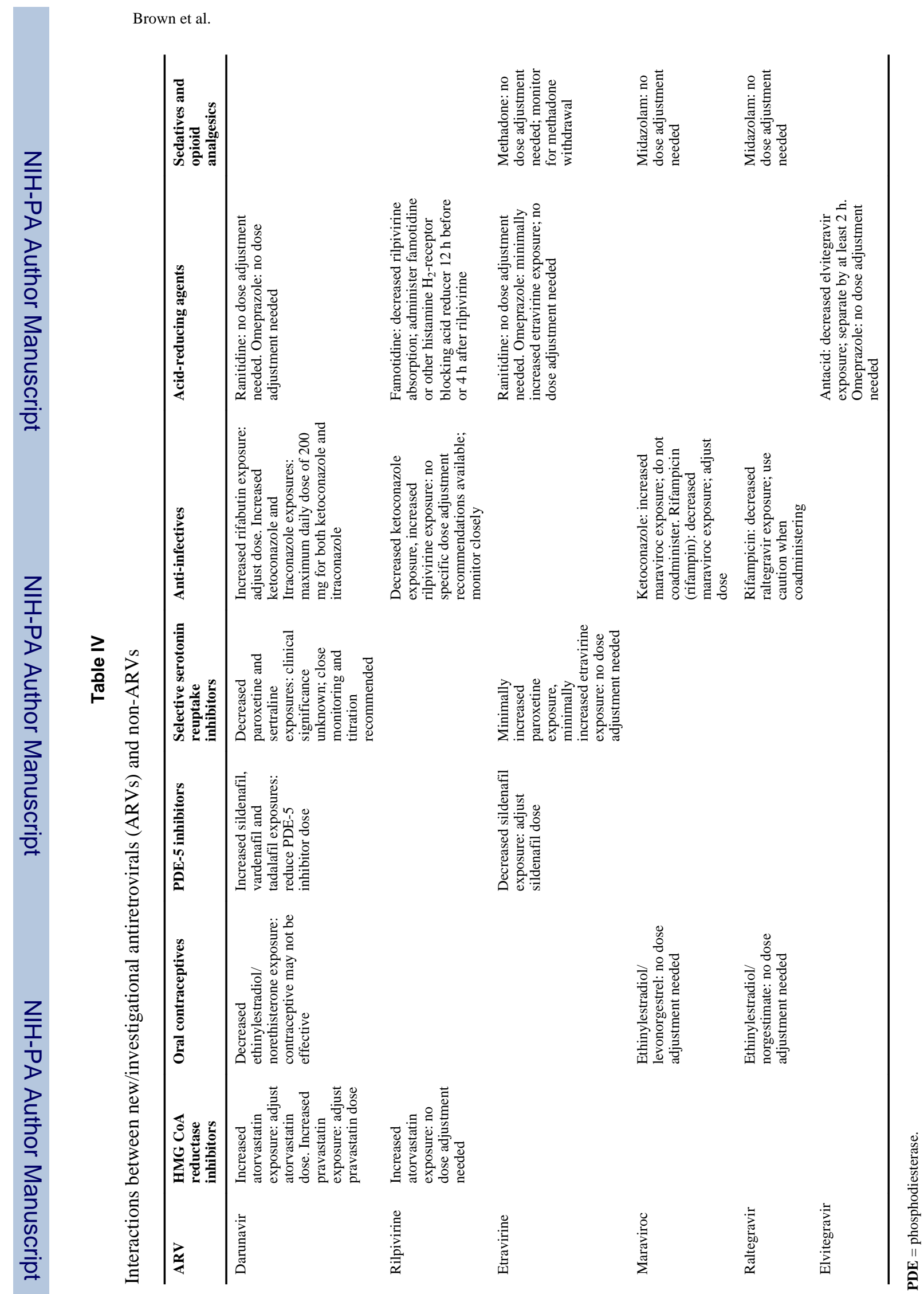

Clin Pharmacokinet. Author manuscript; available in PMC 2010 April 21. 